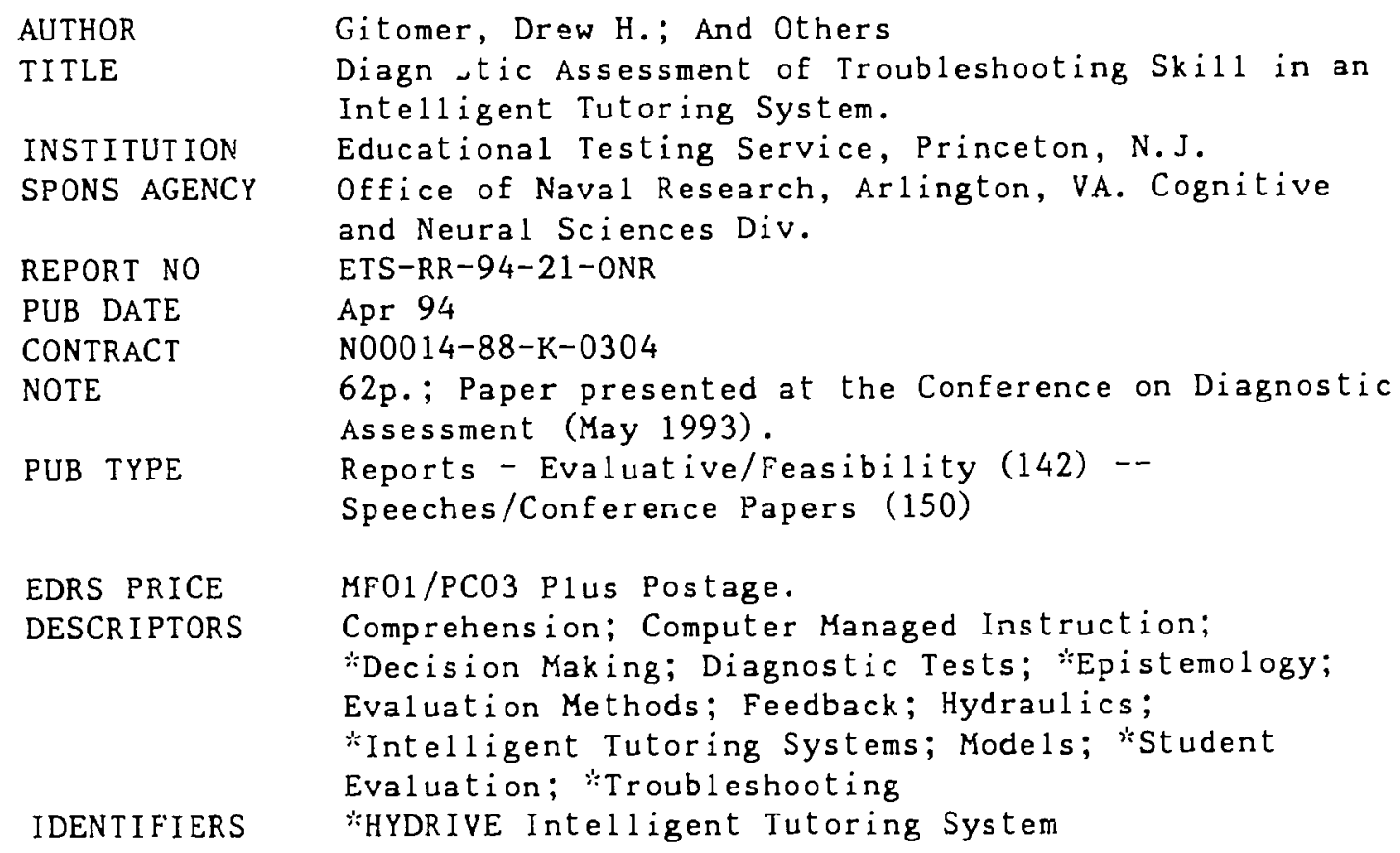

\title{
ABSTRACT
}

This paper lays out the rationale and implementation of student modeling and updating in the HYDRIVE intelligent tutoring system (ITS) for aircraft hydraulic systems. An epistemic level of modeling concerns the plans and goals students are using to guide their problem solving, as inferred from specific actions in specific contexts. These results update a student model constructed around more broadly defined aspects of system understanding, strategic knowledge, and procedural skills. Meant to support inferences that transcend particular problem states, this level of student modeling moderates feedback and instructional decisions in HYDRIVE. The applicability of this approach to student modeling in other learning domains is discussed. (Contains 9 figures, 1 table, and 26 ref $\operatorname{lichces.)}$ (Author) 


\section{DIAGNOSTIC ASSESSMENT OF TROUBLESHOOTING SKILL IN AN INTELLIGENT TUTORING SYSTEM}

Drew H. Gitomer

Linda S. Steinberg

Robert J. Mislevy
This research was sponsored in part by the Cognitive Science Program

Cognitive and Neural Sciences Division

Office of Naval Research, under

Contract No. N00014-88-K-0304

$R \& T 4421552$

Robert J. Mislevy, Principal Investigator

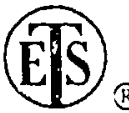

\section{Educational Testing Service}

Princeton, NJ

April 1994

Reproduction in whole or in part is permitted for any purpose of the United States

Government.

Approved for public release; distribution unlimited. 
Public reporting Jurcen lor this collection of in formation is esiimated to dverage i hour der :esponse, including the iıme for reviewing instructions, searching existing data sources gathering and maintaining the data needed, and completing and reviewing the coliection of intornation Send comments regarding this burden estimate or any otheraspect of this collection of intormatin.

\begin{tabular}{l|l|l|l} 
1. AGENCY USE ONLY (Leave blank) & 2. REPORT DATE & 3. REPORT TYPE AND DATES COVERED
\end{tabular}

\begin{tabular}{l|l|l} 
1. AGENCY USE ONLY (Leave blank) & $\begin{array}{l}\text { 2. REPORT DATE } \\
\text { March } 1994\end{array}$ & $\begin{array}{l}\text { 3. REPORT } \\
\text { Final }\end{array}$ \\
\hline
\end{tabular}

4. TITLE AND SUBTITLE

Diagnostic Assessment of Troubleshooting Skill in an Intelligent Tutoring System

6. AUTHOR(S)

Drew H. Gitomer, Linda S. Steinberg and Robert J. Mislevy

G. N00014-88-K-0304

PE. $\quad 61153 \mathrm{~N}$

PR. RR 04204

TA. RR 04204-01

WU. R\&T 4421552

7. PERFORMING ORGANIZATION NAME(S) AND ADDRESS(ES)

Educational Testing Service

8. PERFORMING ORGANIZATION REPORT NUMBER

Rosedale Road

RR-94-21-ONR

Princeton, NJ 08541

\section{SPONSORING / MONITORING AGENCY NAME(S) AND ADDRESS(ES)}

Cognitive Sciences

Code $1142 \mathrm{CS}$

Office of Naval Research

Arlington, VA 22217-5000
10. SPONSORING / MONITORING AGENCY REPORT NUMBER N/A

\section{SUPPLEMEN TARY NOTES}

None

12a. DISTRIBUTION / AVAILABILITY STATEMENT

Unclassified/Un].imited 12b. DISTRIBUTION CODE

N/A

\section{ABSTRACT (Maximum 200 wor , s)}

This paper lays out the rationale and implementation of student modeling and updating in the HYDRIVE intelligent tutoring system (ITS) for aircraft hydraulic systems. An epistemic level of modeling concerns the plans and goals students are using to guide their problem-solving, as inferred from specific actions in specific contexts. These results update a student model constructed around more broadly defined aspects of system understanding, strategic knowledge, and procedural skil.1s. Meant to support inferences that transcend particular problem states, this level of student modeling moderates feedback and instructional decisions in HYDRIVE. The applicability of this approach to student modeling in other learning domains is discussed.

.

\section{SUBJECT TERMS}

Bayesian inference networks, causal probability networks, cognitive models, HYDRIVE, intelligent tutoring systems.

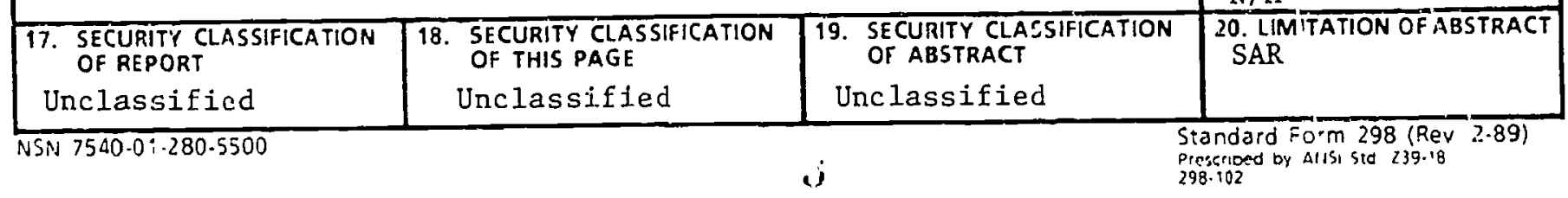


Diagnostic Assessment of Troubleshooting Skill in an Intelligent Tutoring System 1

Drew H. Gitomer, Linda S. Steinberg and Robert I. Mislevy Educational Testing Service 
Copyright ( 1 1994. Educational Testing Service. All rights reserved

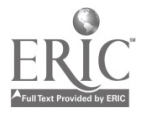

5 
Diagnostic Assessment of Troubleshooting Skill in an Intelligent Tutoring System

Drew H. Gitomer, Linda S. Steinberg and Robert J. Mislevy

Educational Testing Service

All intelligent tutoring systems (ITSs) are predicated on some form of student modeling to guide $t$ ttor behavior. Decisions based on inferences about what a student knows and does not know can affect the presentation and pacing of problems, quality of feedback and instruction, and determination of when a student has completed some set of tutorial objectives. In this paper, we describe a view of student modeling that, in the rourse of implementing principles of cognitive diagnosis, takes advantage of concepts and tools developed in the areas of probability-based reasoning, educational assessment, and psychometrics in an attempt to develop a generalizable framework for student modeling within intelligent tutoring systems.

Student models in an ITS can fulfill at least three functions. First, given a set of instructional options, a student model provides information suggesting which of the available choices is most appropriate for an individual (Ohlsson, 1987). ITS's, because they explicitly represent domains of knowledge and task performance, prescribe instruction that should be designed at a level of cognitive complexity that will lead to successful performance and understanding. Without explicit representation of task performance, instruction may be focused on non-essential features of the domain being tutored (e.g., Kieras, 1988). Second, student models in ITS's enable prediction of the actions a student will take based on an analysis of the characteristics of a particular problem state with respect to what the system infers about the student's understanding (Ohlsson, 1987). Given some inferred understanding of students and of problems, one ought to be able to more accurately predict future performance than if no model has been specified. The degree to which student actions conform to these predictions is an indication of the validity of the inferences made by the student model. Third, the student model enables the ITS to make claims about the competency of an individual with respect to various 
problem-solving abilities. These claims are a shorthand that help to decide about whether a person is likely to be capable of negotiating a particular situation and can help the tutor make decisions about problem selection and exit criteria from a program of instruction.

In order to fulfill all three functions, we propose an ITS student model architecture that attempts to satisfy a set of cognitive and psychometric criteria that we believe to be essential to any successful student model, particularly those embedded in an ITS. These principles har: 2 become embodied in a system called HYDRIVE, an intelligent video-disc based tutoring/assessment system designed to facilitate the development of troubleshooting skills for the F-15 hydraulics systems ${ }^{2}$. Criteria for Student Modeling

The goal of the HYDRIVE student model is to diagnose the quality of specific troubleshooting actions and also to infer student understanding of general constucts such as knowledge of systems, strategies, and procedures that are associated with troubleshooting proficiency. In designing the student modeling component for HYDRIVE, we attempted to satisfy the following five criteria of student modeling.

1. Assessment of generalized constructs. Wenger (1987) describes three levels of information that can be addressed by an ITS. The behavioral level of information typically has been concerned with the correctness of student behaviors referenced against some model of expert performance. Early ITSs such as SOPHE-I (Brown, Burton \& Bell, 1975) contrasted student behaviors with domain performance simulations as a basis for offering corrective feedback. The epistemic level of information is concerned with particular knowledge states of individuals. Using techniques such as model tracing (e.g., Anderson, Corbett, Fincham, Hoffman, \& Pelletier, 1992, Johnson \& Soloway, 1985), and issue tracing (e.g., Lesgold, Eggan, Katz, \& Rao, 1992), these tutors make inferences about the goals and plans students are using to guide their actions during problem solving. Feedback is responsive to "what the student is thinking." The individual level of information addresses broader assertions about the individuai that transcend particular problern states. 
Whereas the epistemic level of diagnosis might lead to the inference that "the student has a faulty plan for procedure $X$ ", the individual level of information might include the assertion that "the student is poor at planning in contexts $A$ and B."

It is this individual level of information that has received the least attention in the field of intelligent tutoring assessment. Traditional psychometrics, on the other hand, has focused almost exclusively on clā ns about individuals while ignoring epistemic levels of information. An assertion is made, for example, that an individual has high ability in mathematics, yet the epistemic conditions that characterize high ability are never explicitly recognized. By recognizing and bridging between both individual and epistemic levels of information, an assessment model can have both the epistemic specificity to facilitate immediate feedback in a problem-solving situation, and also the generality of individual information to suggest the appropriate sequencing of probiems, the moderation of instruction, and the determination of general levels of proficiency.

To meet this objective, the HYDRIVE student model is designed to make generalized claims about aspects of student troubleshooting proficiency based on detailed epistemic analysis of particular actions within the system. These generalized claims describe individual understanding at a level abstracted from any single problem solving situation. Abstractions, such as a student's strategic understanding, become the target constructs of the troubleshooting domain that are the focus of instruction.

2. The student model as an implicit theory of performance. ITS student models typically have been "runnable" in that they are designed to generate student performance and produce the same types of errors and successes that an actual student would if given a particular problem. The HYDRIVE student model's generali. ed abstractions are not runnable in the same sense. It will not generate specific actions, but it will prcdict the likelihood of occurrence for different classes and quality of actions. The student model is however, an implicit theory of 
performance since the model-generated profile of student competencies predicts how students will perform on different problems and in different problem situations.

Such a theory of performance can also be viewed as a curricular goal structure. Lesgold (1988) has argued that ITSs, though they explicitly represent requisite knowledge to perform a task, have failed to articulate knowledge interrelationships in anything approximating a curriculum structure. The student model of HYDRIVE attempts to represent student understanding at the grain size of overarching curricular goals. Expert-like actions, for example, would lead to inferences that a student had good system understanding, an overarching curricular goal. The student model would not represent explicitly however, which specific system components and their features were well understood.

The HYDRIVE student model contains two leveis of features. The first level can be construed as epistemic features, direct infere ${ }_{11}$ ces of student understanding referenced to actions taken at a particular problem state. The second level of features represents the generalized constructs of individual proficiency. Links between the generalized constructs and the directly inferred features represent an implicit theory of performance in this domain. So, for example, the student model suggests that an incividual with high strategic understanding is more likely to take an action that results in information about multiple components, when this is possible, than is an individual who is judged to have poor strategic understanding.

3. The student model as a predictor of actions. Typically, ITS student models have not supported prediction of actions based on higher-level assertions about individual competence. Prediction is more often confined to the relatively local level of plans, goals, and knowledge in highly specified contexts. An explicit goal of the HYDRIVE student model is to provide a mechanism for making predictions of student actions based on estimates of higher-order constructs. The ability to make such predictions creates the opportunity to directly test the adequacy of the model by evaliating how well student actions are predicted. The testability of student model 
adequacy, particularly with respect to higher-order constructs, is a feature missing from most ITSs.

4. The student model as probabilistic. ITS modeling decisions have either been deterministic or at most, probabilistic in a limited sense. In deterministic models, a student is judged as having either evidenced or not evidenced some underlying skill or understanding via examining student behavior. For example, many of the bug-like approaches (Brown \& Burton, 1978; Spohrer, Soloway \& Pope, 1986), make definitive inferences that a student is operating under one conception or another.

Obviously, such inferences of unobservable reasoning processes can never be certain. To address uncertainty, a number of systems have adopted local probabilistic representation schemes that assign some likelihood values to inferences made by the student model. These systems do not use probabilistic reasoning to update inferences except at the most local levels. Updates follow relatively ad-hoc, albeit sensible updates of likelihood, that do not reflect the interdependencies of probabilities that should exist within a structural network that is governed by probability theory. Anderson's (Anderson \& Reiser, 1985) LISP tutor is one such example of this approach.

Lesgold, Eggan, Katz \& Rao (1992) have modeled student performance using a fuzzy variable methodology. Evaluated actions update unobservable variables in a consistent, but non-probabilistic manner. Though the rules of probability theory (e.g., $\Sigma \mathrm{p}_{1} \ldots \mathrm{p}_{\mathrm{n}}=1$ ) are preserved locally, probabilistic relationships between variables are not specified. This lack of specification precludes the testability of interdependencies among variables.

The HYDRIVE assessment scheme takes advantage of advances in probabilistic networks to characterize and assess the quality of a student model through the application of probability theory. Mislevy (Mislevy, 1993; Mislevy, Yamamoto, \& Anacker, 1992) has presented the logic for the application of this methodology to issues of assessment. Essentially, it combines the statistical power of 
probability theory to networks that are structures derived through the cognitive analysis of task domains. Probability theory provides a sound approach to evaluate, modify, and test student models predicated on cognitive understanding ch task performance.

5. The student model as generalizable to other domains. The HVDRIVE model is designed to be generalizable to other domains aside from technical troubleshooting. If there exists a cognitive model of domain performance in which the interrelationship between features can be specified probabilistically, and if student behaviors within the tutor can be evaluated in terms of performance on some subset of those features, than this approach should be feasible. The power of this approach derives from the explicit representation of relationships between features, not from any particular qualities or the features themselves. Therefore, Mislevy has had success in modeling such tasks as arithmelic (Mislevy, 1993) and proportional reasoning (Beland \& Mislevy, 1992); in addition to the current effort.

\section{HYDRIVE's Design and Rationale}

In this section, we overview the HYDRIVE system in order to introduce the context in which this student modeling approach was developed. HYDRIVE is designed to simulate many of the important cognitive and contextual features of troubleshooting on the flightline. Hydraulics systems are involved in the operation of fight controls, landing gear, the canopy, the jet fuel starter, and aerial refueling. Technicians in this career field diagnose and service F-15 problems on the flightline, where the aircraft takeoff and land. Their mission is to keep the aircraft flying as regularly as possible. In addressing problems, they typically isolate faulty components and replace them. Actual repair of any faulty component is performed by other individuals in a shop environment.

HYDRIVE presents problems as video sequences in which a pilot, who is about to take off or has just landed, describes some aircraft malfunction to the. hydraulics technician (e.g., the rudders do not move during pre-flight checks). Once 
the problem is presented, HYDRIVE's interface ailows the student several options. The student can perform troubleshooting procedures by accessing video images of aircraft components and acting on those components. Alternatively, the student can choose to review technical support materials, including hierarchically organized schematic diagrams, which are available on line. Students can also make their own instructional selections at any time during troubleshooting, in addition to or in place of instruction that is recommended. A schematized version of the interface is presented in Figure 1.

Insert Figure 1 about here

The general structure of HYDRIVE is presented in Figure 2, with the modules responsible for student modeling highighted. Students act on the aircraft through the interface. The state of the aircraft system, including changes brought about by user actions, is represented in the system model. The quality of student troubleshooting is monitored by evaluating how the student uses information in the system model to direct troubleshooting actions. As a result of decisions made by the student model, instructional help may be suggested by the tutor. The student model, then, is best understood in terms of its relationship to the system and instructional models.

Insert Figure 2 about here

The goal of creating an assessment scheme that represents an implicit model of student performance (Criterion 2) must rely on an understanding of the nature of task performance by individuals with different levels of expertise. Further, as an intelligent tutoring system, both the tutoring or instructional goals and the assessment constructs ought to derive from a common understanding. Therefore, the rationale for HYDRIVE's design was established through the application of the 
PARI cognitive task analysis methodology developed in the Basic Job Skills Program of the Armstrong Laboratories (Means \& Gott, 1988; Gitomer et al, 1992). The purpose of this analysis was to uncierstand the critical cognitive attributes that differentiate proficient $t^{2} / \mathrm{m}$ less-proficient performers in the domain of troubleshooting aircraft hydraulic systems. PARI analysis is a structured protocol analysis scheme in which mainteitance personnel are presented a problem and then asked to solve the problem mentally, detailing the reasons for their action (Precursor), and the Action that they would take. The technician is presented a hypothetical Result and then asked to make an Interpretation of the result in terms of how it modifies understandirg of the problem. Technicians are also asked to represent their understanding of the specific aircraft system they are troubleshooting by drawing a block diagram of the suspect system.

Proficiency differences were apparent in three fundamental and interdependent areas: system understanding, strategic understanding, and procedural understanding, all of which are necessary for formation of an effective mental model of a system. These are the generalized constructs upon which the content of HYDRIVE is based. The coherence of the assessment approach, and the tutor itself, is due to the fact that the constructs monitored in the student model profile and the instructiona? goals all derive from the same PARI cognitive task analysis.

System understanding. System understanding consists of how-it-works knowledge about the components of the system, knowledge of component inputs and outputs, and understanding of system topology, all at a level of detail nezessary to accomplish necessary tasks (Kieras, 1988). Novices did not evidence appropriate mental models, as represented by the block diagrams they were asked to draw, of any hydraulic systern sufficient to direct troubleshooting behavior. In most cases, novices were unable to generate any mental mcdel at all. The "models" they did generate generally included a small number of unconnected components that were so vague as to be of minimal use in troubleshooting. The operation of any given 
aircraft system was essentially a black box for these technicians. Mental models for the experts, also represented by the block diagrams they were asked to draw, tended to be accurate representations of the specific aircraft system, including connections between components and between power systems. Experts' mental models generally evidenced a full understanding of how individual components operated within any given system, even though they did not understand the internal workings of these same components, which they had only to replace. Examples of expert and novice representations for the same problem (rudders fail to deflect with input) are presented in Figures 3 and 4.

Insert Figures 3 and 4 about here

Experts also demonstrated a principled sense of hydraulic system functioning independent of the specific F-15 aircraft. They seemed to understand classes of components beyond the specific instances found in a particular aircraft or aircraft system. Their knowledge was hierarchically organized according to the functional boundaries of the system. For a flight control system for example, hierarchical and generic clusters of components would include at least a switching system (for emergency backup), an electrically controlled input system, a hydraulic power source, and a set of hydraulic controls (the servo-actuators and related valves). At an even higher level, experts also understood the shared and discrete characteristics of flight control and other hydraulic-related aircraft systems.

The most important consequence of this type of understanding is that, in the absence of a completely pre-specified mental model of a system, experts are able to construct a mental model using schematic diagrarns. They are able to flesh out the particulars given their basic functional understanding of how hydraulic systems work in the context of the aircraft. Experts are also able to use their knowledge of failure characteristics to help isolate a problem to a particular aircraft or power system. For example, intermittent failures have a higher likelihood of being 
electrical rather than hydraulic in nature.

Strategic understanding. Novices did not employ very effective troubleshooting strategies either. That is, they demonstrated little ability for using system understanding to perform tasks that would allow them to draw inferences about the problem from the behavior of the system (Kieras, 1988). In many cases, the only strategy available to these individuals was to follow designated procedures in technical materials, even when it wasn't clear that the symptom matched the conditions described in the written manuals. While these materials, known as Fault Isolation Guides (FIs) can be useful tools, novices frequently fail to understand how an FI procedure serves to constrain the problem space. It is not always clear to the novice what information about the system is addressed by a particular FI procedure. Even in those cases where the technician evidences some system understanding, a serial elimination strategy, where components adjacent to each other are operated on in order, is frequently used. This strategy allows the technician to make claims only about a single component at a time. A space splitting strategy, conversely, dictates the use of actions that provide information about many components at one time, making this type of strategy much less costly. Norices do not evidence a strategic orientation that minimizes the costs of troubleshooting procedures while problem solving.

Expert strategies are much more effective, select approaches that maximize information gain and minimize the expense of obtaining such information. Experts try to use effective space-splitting strategies which isolate problems to a subsystem through the application of relatively few and inexpensive procedures that can rule out large sections of the problem area. They almost always attempt to eliminate and localize power system failures (eg., functional failure due to something like a blown fuse) first; then activate different parts of the system until they find the path a long which the failure manifests itself; and finally localize the failure to a specific segment of this path (i.e., mechanical, electrical, hydraulic). The only exception to this general strategic model occurs when an exceptionally cheap action is available 
that provides some information about the system. The ability to balance cost (measured in time to complete an action) and information benefit is one of the hallmarks of expertise in this domain. Experts are able to evaluate results in terms of their mental models of the system and make determinations of the integrity of different parts of the aircraft. When experts consult the FI guide, they do so as a reference to double check whether they may be overlooking a particular problem source. They may execute a recommended Fl procedure, but never in a purely procedural and mechanical fashion. For experts, an FI action is immediately interpreted in terms of and integrated with their system mental model.

Those technicians with intermediate skills are quite variable in their use of strategies. When individuals have fairly good system understanding, they frequently evidence effective troubleshooting strategies. When system understanding is weak though, technicians often default to FI and serial elimination strategies. If intelmediates have a basic understanding of troubleshooting strategy that is dependent on system understanding, then the implication for instruction for these individuals is to focus on system understanding. For novices, the evidence suggests that direct strategy instruction may also be necessary.

Procedural understanding. Every component can be acted upon through a variety of procedures which provide information about some subset of the aircraft. Information about some types of components can only be gained by removing and replacing $(R \& R)$ them. Others can be acted upon by inspecting inputs and outputs (electrical, mechanical, and/or hydraulic), and by changing states (e.g., switches on or off, increasing mechanical input, charging an accumulator). Some actions inherently provide information only about the component being acted upon, while other actions can provide information about larger pieces of the problem area, depending upon the current state of the system model. R\&R procedures tend to provide information only about the component being operated upon.

As individuals gain expertise, they develop a repertoire of procedures that can be applied during troubleshooting. Novices are generally limited to $R \& R$ actions 
and the procedures specified in the FI. They often fail to spontaneously use the information that can be provided from studying gauges and indicators and conventional test equipment procedures.

Experts are particularly adept at partially disabling aircraft systems and isolating major portions of the problem area as functional or problematic. For instance, rudders can be controlled through electrical and/or mechanical inputs. By disabling the electrical system, for example, a great deal of information about both the hydraulic and mechanical paths can be obtained.

The relationship between system, strategic, and procedural understanding. A mental model includes information not only about the inputs and outputs of components, but also available actions that can be performed on components. The tendency to engage in certain procedures or strategies is often a function of the structure and completeness of system understanding, rather than the understanding of strategies or procedures in the abstract. Failure to engage in space splitting may be attributable to one of several factors. First, the troubleshooter may not understand the system sufficiently to suggest appropriate points to split the system. Second, the individual may not have available appropriate actions (procedures) that will effectively divide the problem space. A third possibility is that the troubleshooter is simply unaware of how and when to use a space-splitting strategy. For those beyond the novice levels, the greatest reason for ineffective problem solving typically is attributable to poor system understanding. For the more novice individuals, there may even be an absence of a general aircraft system understanding that specifies the relationships between power systems.

Task analysis implications for assessment. This view of troubleshooting expertise has implications for student modeling and corresponding instruction in HYDRIVE. For assessment, failure to execute an effective troubleshooting action may, on the surface, appear to be a strategic failure. However, because a superficial strategic deficit may be due, in fact to an impoverished system understanding, poor problem solving will contribute to a lower estimate of a student's system knowledge 
as well as a lower estimate of strategic knowledge. If a student has exhibited strong strategic understanding on other problems for which good system understanding exists, then the likelihood is greater that the performance deficit on a new problem is directly attributable to a poor system knowledge. The student model must therefore represent the conceptual interdependencies that we assume to exist between different forms of understanding.

HYDRIVE's instruction focuses on effective system understanding and troubleshooting strategies rather than on optimizing actions to take at a given point in a problem. Ineffective actions raise doubts about a student's system understanding, which might suggest instruction targeted towards student construction of appropriate and useful system models. A key instructional strategy is to help students develop a hierarchical model of system understanding that is the critical feature of expert knowledge. HYDRIVE attempts to make this structure explicit through the use of hierarchical diagrams and organized verbal information. The claim is that effective troubleshooting strategies are more likely to be utilized in the presence of such a hierarchical structure.

\section{Implementation of HYDRIVE's Student Model}

There are three primary components to the HYDRIVE student model; the action evaluator, the strategy interpreter and the student profile. These three components depend on information from the system model to produce their results. The strategic goal of troubleshooting is to effectively reduce the problem area: to get as much information about components in the system model, so as either to eliminate them as sources of the failure or pinpoint the failure, in as efficient and cost-effective manner as possible. In HYDRIVE, students' actions are evaluated in terms of the potential information they yield given the current state of the system model. The action evaluator consults the current state of the system model and calculates the effects on the problem area of an action sequence performed by the student on the system model. The strategy interpreter makes rule- 
based inferences about the student's apparent strategy usage based on the quality of information (i.e., quantity and type of problem area reduction) obtained from the action evaluator. Although obtained in a wide variety of situations that síudents arrive in as they work through a problem, these results are expressed in terms of a more abstract set of variables that are meaningful across situations. In the terminology of Mislevy (1993), these are the "observable variables"x. Not all elements of this vector need apply to all situations, but all updating of the student model variables will be mediated in their terms. The results of the strategy interpreter are then used to update the student profile, a network representation of student competence. The network element nodes and relationships are derived from the PARI analysis and are updated across actions and problems. In Mislevy's terms, these more abstractly-defined aspects of competence comprise the student model variables, $\beta$. As described below, a critical activity is specifying the probabilities that students having a given configuration of student-model values would take actions described as various possible values of relevant observable variables; that is, $p(x \mid \beta)$. Each of the student components is described below, but because action evaluation is based on information obtained from states and changes in the system model, we begin with a brief discussion of system modeling in HYDRIVE.

The system model. In HYDRIVE, the student uses the system model to simulate various aircraft states and explore the results of these simulations as a means of finding where in the system the problem resides. A system model is defined as a set of components that are connected by means of inputs and outputs. A component can have any number of inputs and outputs. Connections between components are expressed as pairs of components, the first being the component producing an output to the second in the pair which receives it as an input. These pairings are called edges and are also qualified by the type of power (electrical, hydraulic or mechanical) characterizing the connection. For example, the connection between a rudder and its actuator (the servomechanism which causes it 
to move) would be left rudder servocylinder_left rudder (mechanical) because the actuator produces a mechanical output which the rudder processes as input. Every component has a small set of possible inputs. For example, the landing gear control handle can be in the up or down position. The output of a component is controlled by its input(s) and the internal state of the component. Given a set of inputs, the component will produce one or more outputs, the value of which depends on whether or not the component is working. For example, moving the landing gear handle to the down position will mechanically activate a relay which results in the creation of an electrical path that energizes the mechanisms associated with landing gear operation, assuming none of these components is failed. A failure may cause no output or an incorrect output to be produced.

Every component also has a set of actions (procedures) that can be performed on it. Some components can be set or manipulated (e.g., switches or control handles), others can be checked for electrical function (e.g., relays), and others can be inspected visually (e.g., mechanical linkages).

The system model processes the actions of the student and propagates sets of inputs and outputs throughout the system. A student activates the system model by providing input to the appropriate components and then has the option of examining the results of such actions by observing any other component of the system. Thus, a student can move the landing gear handle down and then go and observe the operation of the landing gear. If the landing gear does not move down, the student may decide to observe the operation of other components in order to begin to isolate the failure.

When a student uses the system model to simulate certain aircraft conditions and then observes the results of that simulation, informaion about the problem area (i.e., which components are still candidates as the source of the failure and which components have been eliminated as possibilities) is presumed available. If the pilot moves the control stick and the rudders move as the student might expect, then an inference can be drawn that all components involved in rudder operation 
when controlled by the stick are functioning correctly and should be eliminated as solirces of the problem. If, however, the rudders do not move as expected, then the siuaent should be able to make the inference that some component is not working correctly along the path activated by the simulation between the control stick and the rudders. Observation of components $a_{i} i$ intermediate points along this active path can provide information about subsets of components involved in this particular way of operating the rudders. If an expected output is not produced at point $x$, then an inference can be made that the faulty component is somewhere between the point of control (e.g., the control stick), and the point of observation.

The action evaluator. For the hydrauli ss technician, the system model appears as an explorable, testable aircraft system in which a failure has occurred. All components belonging to this system are part of the initial problem area, represented as sets of input/output edges. When a student acts to supply power and input to the aircraft system, the effects of this input spread throughout the system model (as values propagated along a continuum of component edges), creating explicit states in a subset of components. This subset is called the active path. If one thinks of the system model as bounded on the one hand by the point(s) at which input is required to initiate system function (point of control), and on the other by its functionally terminal outputs, then an active path typically begins with the one and ends with the other, including all the connections in between. So, for example, an active path can be created for the steering system of an automobile by turning the steering wheel. This action creates an active path extending from the steering wheel (the input boundary, or a point of control of the system) to the tires (the output boundary of the system). For a power steering system the ignition switch is another point of control, since whether or not input is also supplied to turn the engine on affects the contents of the active path (one would be primarily hydromechanical, the other strictly mechanical).

The action evaluator considers every troubleshooting action from the student's point of view in terms of the information that can be inferred with respect 
to effects on the problem area. The action evaluator, in updating its problem area, assumes that the student always makes the correct judgment about whether observations reveal normal or abnormal component states. If, for example, having supplied a set of inputs. a student observes the output of a certain component, which the system model 'knows' is normal, then the student is presumed to infer that all edges on the active path, up to and including the output edge, are functioning correctly and, therefore, remove them from the problem area. If the student, in fact, makes the correct judgment about the observation and the appropriate inferences from it concerning the problem area, then the dynamic problem area that the student model and the student hold correspond and troubleshooting continues smoothly. If, however, the student decides that the observed component output was unexpected, or abnormal, then, at least in the student's mind, all the edges in the active path remain in the problem area, any others would be,$-i$; ininated, and the problem area maintained by the student model begins to diverge significantly from the one present in the student's mind. In this case, subsequent stuäent actions and corresponding evaluations are likely to signal the need $\mathrm{fc}_{\mathrm{i}}$ instruction.

Figure 5 presents a grossly simplified hypothetical problem space for a hydraulics-like system. This system has two points of control which both send electrical signals to electrical components $A$ and $B$ respectively. Both of these signals are sent to an electromechanical component which outputs a mechanical signal to the mechanical component. Hydromechanical components $A$ and $B$ operate by receiving the mechanical signal as well as hydraulic power from hydraulic circuits $A$ and $B$ respectively.

Insert Fizure 5 about here

In this hypothetical model, a number of active paths can be set up to isolate a fault. By activating point of control $A$, the entire system other than the path that 
includes point of control B and electrical B are being tested. If the output from the hydromechanical components is unexpected, then the problem is clearly not associated with point of control B or electrical B edges. If expected output were to be obtained when point of control $B$ is activated, then it is possible to infer that the locus of the fault is point of control $A$ or electrical $A$, for other than these two component edges, the active paths overlap. Other discriminations can be made by selectively disabling hydraulics A and B and observing changes in the output of the hydromechanical devices. In HYDRIVE, the student can use a review function to help compare his or her dynamic idea of the problem area with that maintained by the student model.

The strategy interpreter. Actual strategy evaluation occurs by evaluating changes to the problem area, formally represented as $\mathbf{k}$, the entire series of edges belonging to the system/subsystem where the problem occurs. As a student acts on the system model, $\mathbf{k}$ is reduced, with elements from $\mathbf{k}$ being removed as a result of an action sequence. If a failed component is on the active path, under the assumption that only one component fails at a time (a reasonable assumption in this domain), all edges other then those on the active path are eliminated from $\mathbf{k}$. Upon inspection of any particular component on this path, the system model will also reveal a state which may or may not be expected from the student's perspective. The update of $\mathbf{k}$ stems from an inference that the fault has to be located within the active path and so all other components are removed from consideration. If, however, there is no failed component in the active path, then ali edges in the active path are eliminated from $\mathbf{k}$, while all other component edges remain in the problem area as candidate failure sources. The system model will return states that should be judged normal by the student for component edges along this active path. Also, an individual component is removed from $\mathbf{k}$ whenever the student selects a remove and replace action. Here, the assumption is that the replacement component is operational. However, with remove and replace, an inference can be made only about the output edges of the replaced component. No inferences are 
possible for other components. The student's task is to reduce $\mathbf{k}$ until the problem is solved.

The method for reducing $\mathrm{k}$ is generalizable to any system that is comprised of components in which sequential flow of control can be defined. As long as one can make a judgment about the output state of a component, then inferences can be made about the state of components comprising a subset of the active path, from the point of control to the point of inspection.

When a sequence of actions results in new status information about more than one edge in the problem space, HYDRIVE designates the strategy as a type of space-splitting. HYDRIVE also differentiates between several forms of space splitting. There is power system elimination, which removes power system sources from the problem area (as in checking hydraulic pressure gauges or circuit breakers); there is active path splitting, which activates different combinations of components to achieve a particular system function (as in operating the rudders through the control stick and through the rudder pedals); and there is power path splitting, which either eliminates series of edges having the same power type or locates the failure to a particular power type (as in using electrical backup to replace mechanical function).

Other troubleshooting actions do not set up active paths and do not result in space splitting, but are discrete tests of single components. The most obvious is simply removing and replacing a component and observing whether the change results in a fix to the system. A remove and replace strategy is expensive both in terms of time and equipment, and is recommended only when there is a high degree of certainty that the replaced component is faulty. In the Figure 5 example, the electro-mechanical component could be replaced to test its functionality.

A serial elimination strategy refers to actions that only provide information about one edge at a time. A serial elimination strategy is inferred when one action provides information about one edge and the ensuing action provides information about an adjacent edge. Though the remove and replace strategy is a form of serial 
elimination, HYDRIVE's designation is limited to actions that are not remove and replace actions (such as visual or electrical inspections).

An FI strategy is one in which the student follows procedures designated in an accessed FI guide for three consecutive actions. While such a strategy is not inherently problematic, it is clear that experts and novices use the FI in different ways. Therefore, the evaluation of a set of actions as an FI strategy will result in probes from the instructional model to ensure that the student understands the effects of actions taken.

Other evaluations do not actually infer strategies, but do make claims about the effectiveness of actions taken. Redundant actions are those that do not provide any new information about the problem. It should be noted that some actions are not costly to execute in terms of time or parts. In fact, experts often times will rerun a procedure to replicate and validate a finding. It is only when actions are costly and do not provide any new information that they are considered redundant. Irrelevant actions are those in which a student performs actions on components which are not at all part of any active path in the system of interest in the problem. Replacing the tires when an automobile won't start is an example of an irrelevant action.

The evaluation of the quality of a strategy is conditional upon the problem state at a particular point. While a remore and replace strategy is evaluated as poor when the problem state allows for space splitting, the same strategy is considered to be of better quality when the potential problem causes have been narrowed to one or two candidates. Therefore, within the strategy evaluator there exists a set of rules that characterize $\mathbf{k}$ in terms of the "best" strategy options that are available. Best strategies are strictly a function of the attributes of components in $\mathbf{k}$, and are easily described. As an example, if components in $\mathbf{k}$ represent different power systems, then a potential strategy is to execute an action that will differentiate those components (a power space split). If all component edges in $\mathbf{k}$ represent one power system, such a strategy is not feasible.

HYDRIVt: makes use of a strategic goal hierarchy to identify the optimal 
strategy, given the current state of the problem area. Figure 6 contains HYDRIVE's strategic goal structure. The comparison of the student's strategy and the best strategy available, as calculated by the strategy interpreter, drives the instructional model which makes the strategic goal hierarchy embedded in the student model explicit to the student in the form of prompts, reminders and instructional exercises.

Insert Figure 6 about here

HYDRIVE employs a relatively small number of strategy interpretation rules $(\sim 25)$ to characterize each troubleshooting action in terms of both the student and the best strategy. An example of a student strategy rule is:

IF active path which includes failure has not been created and the student creates an active path which does not include failure and edges removed from $k$ are of one power class, THEN the student strategy is power path splitting.

An example of a best strategy rule is:

If $k$ contains one or more hydraulic power systems. THEN the best strategy is power system elimination.

The student profile. HYDRIVE uses the results of the strategy and action evaluator to update the student profile, represented as a network, using the ERGO (Noetic Systems, 1993) system. The student profile network that includes only a significant portion of the flight control system is presented in Figure 7. The nodes at the right are those that are directly updated through the strategy evaluation. These are thought of as observables. All other nodes can be thought of as constructs which have values determined, in terms of probability distributions for their possible values, by evidence capiured by the observables. Once the observables are set by the strategy evaluation process, the remainder of the network is updated based on 
probabilistic relations among nodes. There is an increasing level of abstraction and generality of inferences about students as one moves to the left of the figure.

The nodes and relationships in the network are derived from the PARI analysis. The PARI analysis supported the idea that proficiency could be characterized by knowledge of systems, strategies, and procedures, and that each of these broad areas could be characterized in terms of constituent parts. Analysis of individual differences in actions le ${ }^{\lambda}$. to the association of con tructs with particular observables. So, for example, the PARI data made it clear that an effective spacesplitting action required knowledge of strategies, procedures, and the particular system being explored. The interdependencies evident in the PARI data are represented in the student profile network.

\section{Insert Figure 7 about here}

All of the nodes in the system, except tor the direct strategy node (StratObs) are represented as having two states, each state having a probability associated with it. We are in the process of exploring more fine-grained distinctions among states. For example, Hawkes, Derry and Rundensteiner (1990), employing a fuzzy reasoning approach, have developed an ITS student model that makes use of seven levels of classification. For the observables, the states are Positive and Negative, for any strategy interpretation provides positive or negative evidence that some knowledge or skill is evident. When updated, they are assigned one of these two discrete states. The other nodes, those that are indirectly updated via the observables, are characterized by the states Strong and Wenk, with a probability associated for each state.

The (splitable) node functions as a description of the current state of $\mathbf{k}$, whether the remaining edges in $\mathbf{k}$ can be reduced by space splitting techniques or not. This is an important function, because the quality of an action can only be considered in the context of what is possible. Rernoving and replacing a 
component, as already noted, is a costly procedure that provides limited information. Therefore, when space splitting is available, this type of action would be associated with less than expert troubleshooting. However, towards the end of a problem solution, when space splitting is no longer possible, remove and replace actions would be considered more positively.

The (StratObs) node takes on one of five values. Space split, Serial climination, Remove and Replace, Redundant and Irrelevant. When the strategy evaluator makes an inference about the most recent sequence of troublesinooting actions, that inference is used to update each of the observables in a manner consistent with a conception of the interdependent nature of troubleshonting performance. As noted, a space splitting strategy not only indicates strategic understanding, but also indicates understanding of the system being troubleshot and the procedures used to effect the troubleshooting. Therefore, a number of observables will be updated positively when a space splitting strategy is inferred. On the other hand, a redundant action is negatively related with strategic understanding, system understanding and procedural skill. Corresponding observables would be assigned negative evidence in the case of a redundant evaluation.

The exact nature of the updating in any case is determined through probability-based inference; having specified the probabilities that a student with known competency values would take each of the potential actions in a given situation, then likeloods induced by the observation of a particular action are combined via Bayes Theorem with previous knowledge about the student to yield updated beliefs about the student-model variables. Thus, the same action can lead to qualitatively different updating when previous states of knowledge differ. For example, a redundant action taken when little is known about a student might lead to downgrading strategic understanding, system understanding, and procedural skill across the board. However, if we previously had evidence for gond system understanding and procedural skill, but little evidence for strategic understanding, 
the downgrading would appear mainly for the latter variable.

Once the observables are set, updating occurs as a function of the probabilistic relations specified in the network. Looking at the left side of Figure 7, Proficiency is a parent of System Knowledge, Procedural Knowledge, and Strategic Knowledge. The probability specification when the network is initially constructed is a response to the question "given that the student is proficient (strong), what is the probability that the student is strong in each of the respective knowledge areas" and also "given that the student is not proficient (weak), what is the likelihood that the student is strong in each of the respective knowledge areas?" If proficient people were always strong in system knowledge and non-proficient individuals were always weak in system knowledge, then the respective probabilities would be close to 0 and 1 .

Such extreme values are seldom helpful in a network. First, it is rare that one can make such certain claims about anything based on someone's performance in an ITS. Second, the specification of such extremes in a network means that a single piece of evidence will have undue influence on the network. Any information that suggests someone has strong strategic knowledge would imply that the person is automatically proficient. By moderating the probabilities, one can temper the updating in the system so that multiple pieces of evidence influence any judgments.

The relative influence of a parent-child relationship is determined by the relative probabilities. Relationships having strong influence are characterized by child probabilities values that differ quilo a bit for different parent conditions. Less influential relationships are characterized by child protability values that are more similar across different parent conditions. So, for example, because the PARI analysis showed that expert-novice differences were better described by strategic differences than by procedural differences (even novices have some expertise for different procedures), given a strong, overall proficiency, the difference in probability values associated with strong and weak understanding, respectively is greater for strategic understanding than it is for procedural understanding. Those probability values are presented in Table 1 . Increasing estimates of strategic understanding will

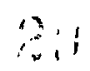


have a stronger impact on estimates of proficiency than will increased estimates of procedural understanding. Similarly, conditional probabilities of observable actions, given values of the student-model variables, were initially specified based on results from PARI traces. Having observed several acknowledged experts' and novices' solutions, we could begin to learn about the relative likelihoods that, say, an expert in a situation in which space-splitting was possible would in fact tuke a spacesplitting action, compared to taking a redundant action, consulting the fault isolutation guide, and so on.

Insert Table 1 about here

Updating from instruction. While HYDRIVE's system model functions as a discovery world for system and procedural understanding, and its student model makes its evaluations based on an implicit strategic goal structure observed in expert troubleshooting, it is only in the instructional model that all of HYDRIVE's goals are made explicit. IYDRIVE's instructional model is driven by the comparison of the student strategy and what HYDRIVE 'thinks' is the best strategy under the prevailing conditions. The student is given great latitude in pursuing the problem solution; the instructional model intervenes with prompts or reminders (i.e., diagnostics) only when a student action constitutes an important violation of the rules associated with the strategic goal structure. As mentioned before, this is most likely to occur when the student's idea of the problem area and the student model's representation of same diverge in some dramatic way. Although HYDRIVE will diagnose and recommend some form of instruction, the actual presentation of any instruction is under direct control of the student who is free to take the instructional model's recommendation, choost other instruction, or continue troubleshooting without any instruction.

HYDRIVE's curriculum is directly informed by the cognitive attributes described in the student profile. The flow of control within the instructional model 
is dictated by the assumption that the student must have adequate system knowledge (a 'runnable' model of the aircraft system) before selecting a troubleshooting strategy. Therefore, a student action which fails to reduce the problem area is first examined in the context of the student profile elements pertaining to system understanding. If these indicate a deficit, instruction is recommended to improve the student's mental model of the physical system. The results of many of these exercises (for example, the 'building' of an aircraft system/subsystem) provide direct evidence of the student's system understanding and cause the related profile elements to be updated. After the point that a student's profile elements indicate proficiency in system inderstanding, ineffective actions are considered in the context of strategic deficit and instruction shifts to emphasize and encourage HYDRIVE's strategic goal structure. Success or failure in certain of these exercises continues to update relevant profile elements.

Setting the probability values. In some situations where there is a large historical database, it is possible to determine empirically the conditional probabilities of observable variables given causal variables ("construct variables" in the present terms). In HYDRIVE, however, we do not have the luxury of analyzing large numbers of solutions from acknowledged experts and novices of various types. Initial values must be set subjectively, and revised as seen appropriate through model-checking activities. In essence, the objective is to encode a network structure and conditional probabilities specifications which correspond with experience to date not only locally (i.e., for a single given action-situation) but globabally (i.e., after accumulating evidence over a series of actions within a problem, then over a series of problems.) The HYDRIVE probabilities were set through an iterative process of making initial estimates, applying data obtained from the PARI analysis as proxies for what the student would do within the HYDRIVE tutor, and then evaluating the behavior of the network to determine whether all nodes were behaving sensibly in terms of the cognitive model. Initial probabilities were problematic in a number of ways. At times, student estimates would be updated too rapidly. At other times, 
they wouldn't be updated despite actions that should have affected estimates of student competence. Other problems included updates moving in unexpected directions. Because all the probabilities are set at the individual node level, the behavior of the entire network is difficult to anticipate. However, by repeatedly applying data, and evaluating the network's behavior, probabilities can be tuned so that the system behaves in a manner consistent with human judgments of performance. These cycles of model building and model criticism are analogous to those required in the construction of, for example, medical expert systems (Andreassen, Woldbye, Falck, \& Andersen, 1987)

Ultimately, as on-line data is obtained, the probabilities can be fine-tuned to an even greater degree. One of the values of this approach is that updates are propagated throughout the system, so that explicit predictions are made about the likeliho d of a type of action occurring given a student profile. For example, a highly proficient student would be more likely to engage in space-splitting behavior given that space-splitting is possible than would a less proficient student. These likelihoods should be evident in the student profile and are able to be tested by evaluating student actions under these conditions. Discrepancies between predicted and observed actions will force refinement of the system.

Example student profiles. The updated profiles resulting from an ineffective and effective solution on a problem in the directional flight control system are presented in Figures 8 and 9, respectively. The ineffective solver first executed a number of actions that followed the FI guide. Following the FI does not result in any updating of the network, for following the FI is not inherently bad or good. Sometimes it makes sense and sometimes it doesn't. Simply using the FI to direct actions is insufficient to make a claim about the student. However, once the FI procedures failed to result in a solution, this solver immediately executed a number of remove and replace actions, a poor strategy at the outset of a problem. Following the remove and replace actions a number of serial eliminations were made. The solution was finally arrived at by removing and replacing the suspect component. 
Insert Figures 8 and 9 about here

The expert solution began with a series of space splitting actions, followed by a number of serial elimination actions, some of which were taken when space splitting was no longer available. This person arrived at the solution in fewer steps than the less effective problem solver, ccncluding the problem by also removing and replacing the suspect component.

Differences in strategy usage and effectiveness of problem-solving are reflected in the networks in Figures 8 and 9. In reading the network, note that for all nodes except (StratObs), the upper bar is the probability of being strong on this node, and the bottom bar is the likelihood of being weak on the node. At the beginning of the problem, all likelihoods were at chance (.5).

As evidence accrues during problem solving some things to note in the network are:

1. The overall difference in likelihoods for the primary constructs of proficiency, strategic knowledge and system knowledge.

2. Differences in likelihoods for intermediate variables. For example, the effective solver is much higher on all of the strategic variables.

3. Relatively minor differences in the procedural likelihoods, an outcome of the probability structure that reflected the findings from the cognitive task analysis chat experts and novices differed least in procedural skill.

4. Largest effects on variables in which the information is most direct, though likelihoods of related variables does change. For example, this problem was from the directional flight control system. Changes in estimates of strength were greatest for the directional system. Nevertheless, likelihoods for the lateral and 1 ungitudinal systems changed to a lesser extent, strengthening for the effective problem solver and weakening for the ineffective problem solver.

5. Changes in the expectations for the observables. Though it is difficult to see 
in the figures, the StratObs distribution makes clear that there is a much greater expectation that the ineffective problem solver will take an action that is irrelevant or redundant than will the effective problem solver.

Controlling the model across problems. The preceding discussion has focused on updating a student model within a given problem, under the implicit assumption that a fixed state of competence is appropriate throughout the course of observation. All information about the student contributes equally + astimates of competence, regardless of when in the course of troubleshooting such information is obtained. The whole point of HYDRIVE, however, is to help students increase their competence! A mechanism to allow for change in the true status of student model variables is therefore necessary. To this end, we are adapting a recency strategy; that is, changes to the student-model variables effected by past problems will be fractionally reduced at the beginning of each problem, so that information from the current problem has more relative impact on our current beliefs than otherwise equally-informative information from past problems. Fractional reduction at the beginning of each problem implies a geometric rate of decay of information from past problems. To the extent that changes do occur over time, our current beliefs about student-model variables always lags their true status somewhat. This approach is more conservative and less risky than attempting to model learning explicitly, as in, for example, Anderson's IISP tutor (Anderson \& Reiser, 1985).

\section{Implications}

We believe we have the beginnings of an assessment model that meets the five criteria set forth earlier in this paper. We are able to move from detailed analysis of discrete actions to make inferences about more general characteristics of an individual. This can be done because of an articulated cognitive framework of performance in this domain. The probabilistic features of this approach prevent ad hoc updating of variables and forces a clear specification of the relationship among 
variables. The probabilistic network also allows for updating to work in two directions, parent-to-child and child-to-parent. The updating scheme allows for testing and evaluation of the student model, due to the explicit predictions that can be made. Most ITS student models are not capable of generating such predictions and are, therefore, incapable of being evaluated in the same way.

This type of student modeling appears to be generalizable to many other tutoring contexts. The most obvious transfer would be to other ITSs in troubleshooting domains. The rules of strategy evaluation are likely to be generalizable since their generalizability resides in the ability to explicitly define strategies in terms of an action's effect on $\mathbf{k}$. While other domains may require the definition of strategies different from the one used by HYDRIVE, as long as these strategies can be referenced to changes in the state of $\mathbf{k}$, or some similar representation, such generalization is quite straightiorward.

ITSs more broadly, regardless of domain, typically have some form of strategy/action evaluator. What many are lacking is the bridge between an action evaluator and claims about the individual. However, it seems that links to the individual are $\mathrm{n} r$-essary if we want to make generalizations from specific problem solving contexts to broader claims about competence and also if we want to direct instruction to issues that transcend particular problem states. Since assessment is fundamentally a process of making generalized inferences based on specific information, this type of approach may contribute to the development of assessment in the ITS world.

More generally though, this approach to assessment has implications for assessment in traditional pedagogical contexts. Features that support student modeling in HYDRIVE are critically important to, though too often absent from, successful classroom instruction. The first requirement is a clear and explicit representation of the domain, or structure of knowledge, to be learned. More than just isolated facts about a domain, the structure of knowledge is a representation of the interrelationships of concepts within a domain. Defining and addressing 
explicit conceptual targets in classrooms is a significant challenge to educational reform in virtually all domains (e,g, Rutherford \& Ahlgren, 1990; National Council of Teachers of Mathematics, 1989).

The second feature is a cognitive model of performance that permits inference of student understanding from task performance. The issue of how one makes valid judgments about student ability out of complex task performance is of central concern in the current educational and assessment debate (Messick, 1992). Part of the solution undoubtedly requires improvements in how evidence is collected and evaluated in classroom settings (e.g., Gitomer \& Duschl, in press). Systematic and detailed exploration of student performance and its relationship to target features of domain understanding will be needed if a move towards problembased learning environments is to succeed. It is worth noting that the difficulties in implementing the HYDRIVE assessment scheme were not particularly technical. By and large, the hurdles involved the explicit definition of the profile and the conceptual mastery of the relationship between student actions and the interpretations that could legitimately be generated based on those actions. These relationships were established through the cognitive task ana!ysis that included a detailed understanding of the domain and performance within the domain. The quality of the cognitive task analysis is undoubtedly the most important feature of this, or any ITS assessment approach.

Mislevy and colleagues have developed prototype assessment models for characterizing proficiency in several relatively constrained domains. These efforts have included proportional reasoning (Béland \& Mislevy, 1992; Mislevy, Yamamoto, \& Anacker, 1992), signed number arithmetic (Thompson, \& Mislevy, 1993), and mixed number subtraction (Mislevy, this voume). In each of these efforts, belief networks were created $\mathrm{cin}$ the basis of cognitive analyses of task performance in the domain. Related efforts in physics problem solving are described by Martin \& VanLehn (this volume).

It is important to recognize that this is not a recommendation that all 
teaching of all domains pursue such a rule-based, systematic approach (Mislevy, in press). Certainly, this methodology is more appropriate for some disciplines than others. Equally certain, only a subset of any disciplinary focus would benefit from this type of approach. However, for those arenas of understanding that are highly structured, and that have clear rules for navigating within that structure, this form of curricular specification and assessment should prove to be beneficial. 


\section{References}

Anderson, J. R., Corbett, A. T., Fincham, J. Mi., Hoffman, D., \& Pelletier, R. (1992).

General principles for an intelligent tutoring architecture. In J.W. Regian and V.J. Shute (Eds.), Cognitive approaches to automated instruction, (pp. 81-106). Hillsdale, NJ: Lawrence Erlbaum .

Anderson, J.R., \& Reiser, B.J. (1985). The LISP tutor. Byte, 10, 159-175.

Andreassen, S., Woldbye, M., Falck, B., \& Andersen, S. K. (1987). MUNIN - A causal probabilistic network for interpretation of electromyographic findings.

Proceedings of the 10th International Joint Conference on Artificial Intelligence, 366-372.

Béland, A., \& Mislevy, R.J. (1992). Probability-based inference in a domain of proportional reasoning tasks. ETS Research Report 92-15-ONR. Princeton, NJ: Educational Testing Service.

Brown, J. S. \& Burton, R..R. (1978). Diagnostic models for procedural bugs ir! basic mathematical skills. Cognitive Science, 2 155-192.

Brown, J. S. Burton, R. R. \& Bell, A. G. (1974). SOPHIE: a sophisticated instructional environment for teaching electronic troubleshooting. BBN REPORT 2790. Bolt Beranek and 'vewman, Inc. Cambridge, MA.

Gitomer, D. H., Cohen, W., Freire, L., Kaplan, R., Steinberg, L., \& Trenholm, H. (1992). The Software Generalizability of HYDRIVE. Princeton, NJ: Educational Testing Service. (Armstrong Laboratories Progress Report).

Gitomer, D. H. \& Duschl, R. A. (in press). Moving towards a portfolio culture in science education. S. Glynn \& R. Duits (Eds.). Learning science in the schools: Research reforming practice. Washington, D.C.: American Association for the Advaricement of Science.

Hawkes, L.W., Derry, S.J. \& Rundensteiner, E.A. (1990). Individualized tutoring using an intelligent fuzzy temporal relational database. International Journal of Man-Machine Studies. 33, 409-429. 
Johnson, W. L. \& Soloway, E. (1985). PROUST: An automatic debugger for Pascal programs. Byte, 10, 179-190.

Kieras, D. E. (1988). What mental model should be taught: Choosing instructional content for complex engineered systems. In M. J. Psotka, L. D. Massey and S. A. Mutter (Eds.), Intelligent tutoring systems: Lessons learned, (pp. 85-111). Hillsdale, NJ: Lawrence Erlbaum.

Lesgold, A.M. (1988). Toward a theory of curriculum for use in designing intellgent instructional systems. In H. Mandl and A. Lesgold (Eds.) (pp. 114-137). Learning issues for intelligent tutoring systems. New York: Springer Verlag.

Lesgold, A. M., Eggan, G., Katz, S., \& Rao, G. (1992). Possibilities for assessment using computer-based apprenticeship environments. In J. W. Regian and V.J. Shute (Eds.), Cognitive approaches to automated instruction, (pp. 49-80). Hillsdale, NJ: Lawrence Erlbaum.

Means, B., \& Gott, S. P. (1988). Cognitive task analysis as a basis for tutor development: Articulating abstract knowledge representations. In M. J. Psotka, L. D. Massey and S. A. Mutter (Eds.), Intelligent tutoring systems: Lessons learned, (pp. 35-58). Hillsdale, NJ: Lawrence Erlbaum.

Messick, S. (1992). The interplay of evidence and consequences in the validation of performance assessments. (ETS RR-92-39). Princeton, NJ: Educational Testing Service.

Mislevy, R.J. (in press). Test theory reconceived. Iournal of Educational Measurement.

Mislevy, R.J. (1993). Probability-based inference in cognitive diagnosis. ETS Research Report 93-xx-ONR. Princeton, NJ: Educational Testing Service.

Mislevy, R.J., Yamamoto, K, \& Anacker, S. (1992). Toward a test theory for assessing student understanding. In R.A. Lesh \& S. Lamon (Eds.), Assessments of authentic performance in school mathematics (pp. 293-318). Washington, DC: American Association for the Advancement of Science. (Also available as RR-91-32-ONR. Princeton: Educational Testing Service.) 
National Council of Teachers of Mathematics (1989). Curriculum and evaluation standards for school mathematics. Reston, VA: NCTM.

Noetic Systems (1993). ERGO v. 1.2 (software), Baltimore, MD.

Ohlsson, S. (1987). Some principles of intelligent tutoring. In R. W. Lawler and M. Yazdani (Eds.), Artificial intelligence and education (Volume 1), (pp. 203237). Norwood, NJ: Ablex.

Rutherford, F. J. \& Ahlgren, A. (1990). Science for all Americans. New York:

Oxford University Press.

Spohrer, J.C., Soloway, E., \& Pope, E. (1986). A goal/Plan analysis of buggy Pascal programs. Human-Computer Interaction, 1, 163-207.

Thompson, T. D. \& Mislevy, R. J. (1993). An inference network representation for studying students' knowledge of signed number arithmetic. Presented at the annual meeting of the American Educational Research Association, Atlanta, GA.

VanLehn, K. (1988). Student modeling. In M. C. Polson \& J. J. Richardson (Eds.), Foundations of intelligent tutoring systems, (pp. 55-78). Hillsdale, NJ: Lawrence Erlbaum.

Wenger, E. (1987). Artificial intelligence and tutoring systems. Los Altos, CA: Morgan Kaufmann. 
Notes

1. This work was originally presented at the Conference on Diagnostic Assessment, cosponsored by American College Testing and the Office of Naval Research in May 1993. We are grateful to Duan-Li Yan and Lauren Nuchow for their technical assistance in the development of the student profiles. We also thank Isaac Bejar for helpful comments on a previous version of the paper.

2. HYDRIVE has been generously supported by Armstrong Laboratories of the United States Air Force. We are indebted to Sherrie Gott and her staff for their contribution to this effort. The views expressed in this chapter are those of the authors and do not imply any official endorsement by any organizations funding this work. 
Figures

Figure 1. A schematized version of the HYDRIVE interface.

Figure 2. The structure of the HYDRIVE tutoring/assessment system.

Figure 3. An expert representation of a flight control problem produced during the PARI task analysis.

Figure 4. A novice representation oi a flight control problem produced during the PARI task analysis.

Figure 5. Hypothetical problem space for a hydraulics-like system.

Figure 6. HYDRIVE's strategic goal structure.

Figure 7. A portion of the HYDRIVE student profile that includes the flight control system nodes, as well as all strategy and procedure nodes.

Figure 8. Updated profile for an ineffective solution.

Figure 9. Updated profile for an effective solution. 
Table 1

Network Probabilities for Strategic and Procedural Understanding Given Proficiency Level

\section{Farent - Proficiency}

Child

Strong Weak

Strong

Strategic

Understanding

Weak

.20

.80

Strong

.52

.48

Procedural

Understanding 


\section{SYSTEM INTERFACE}

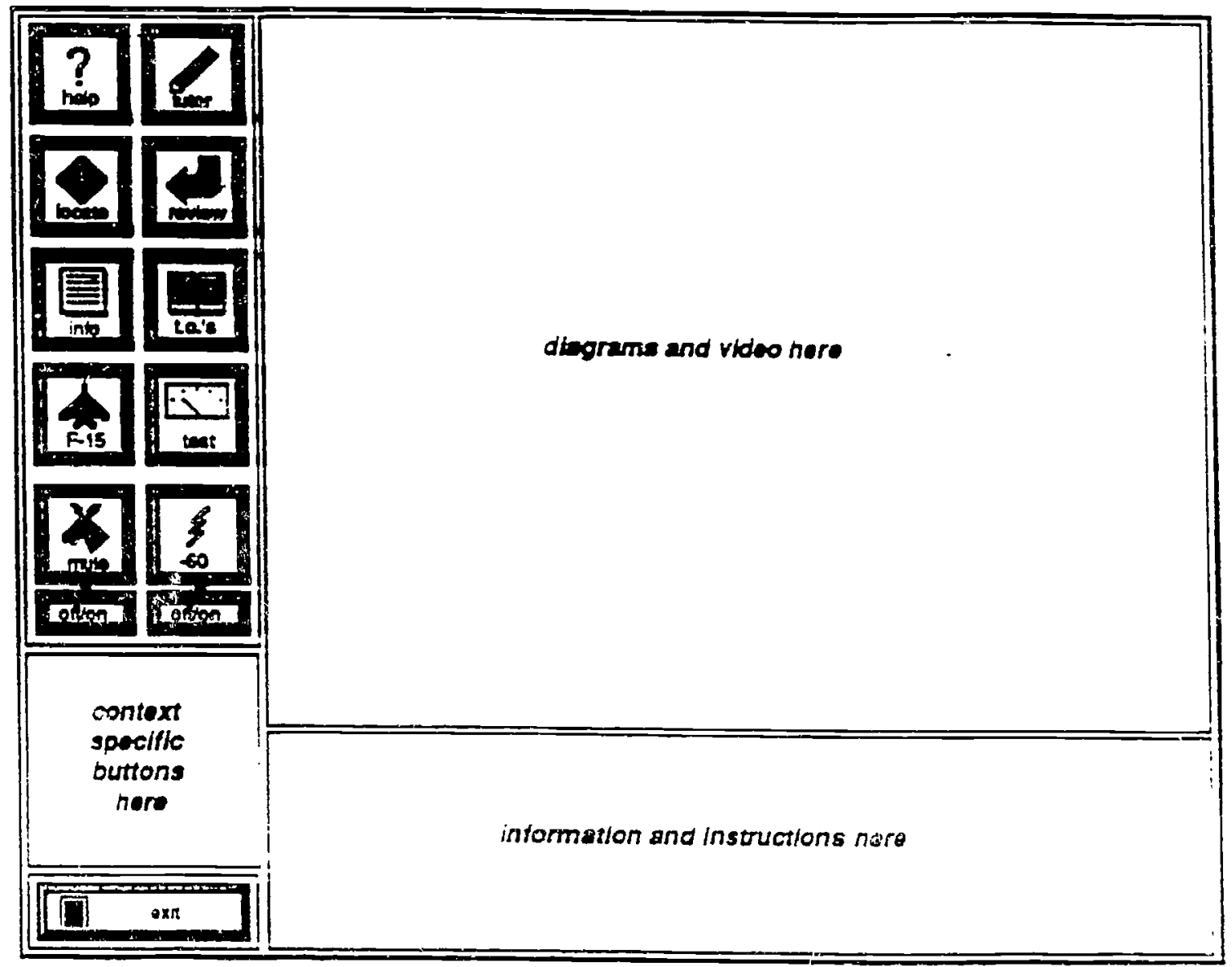




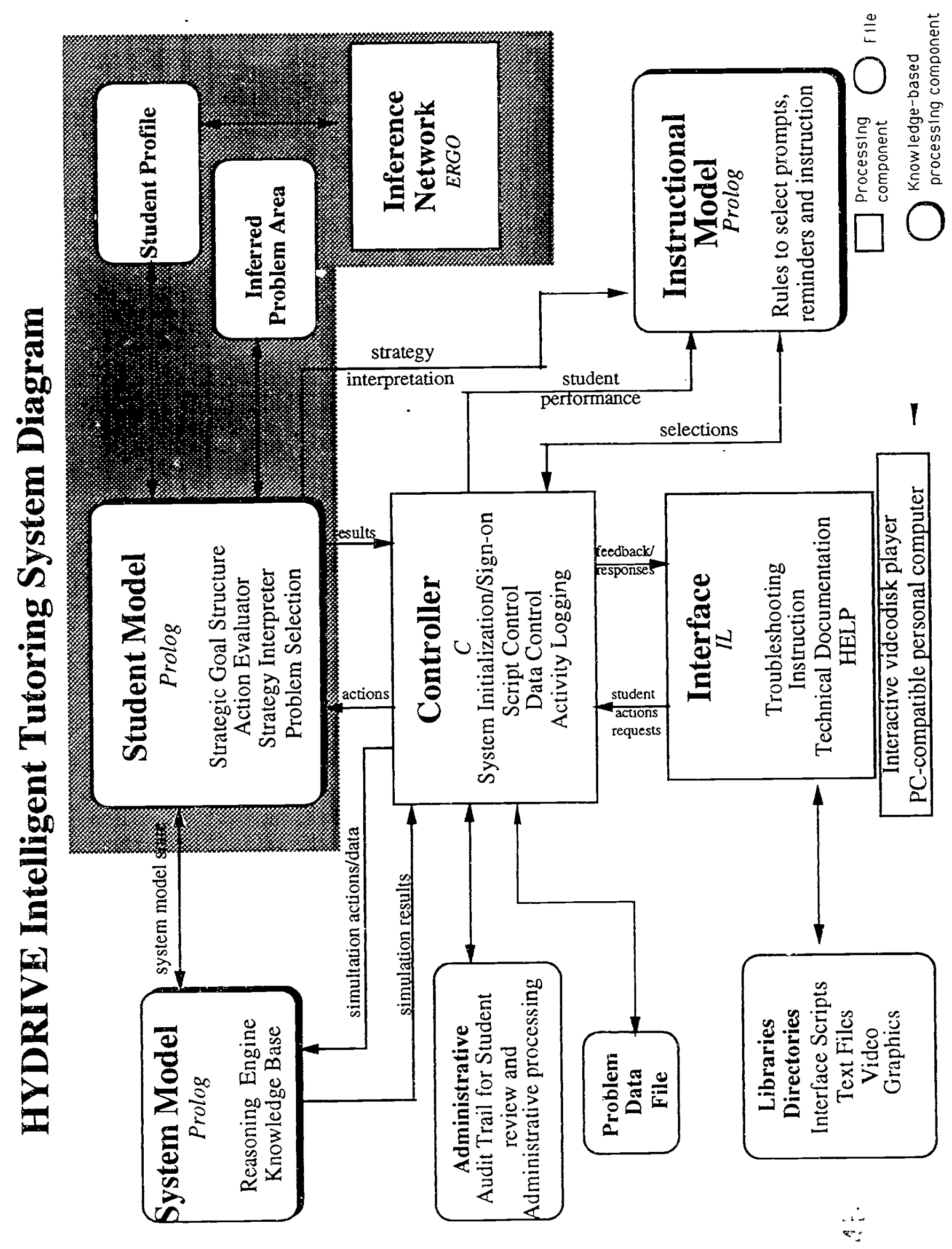




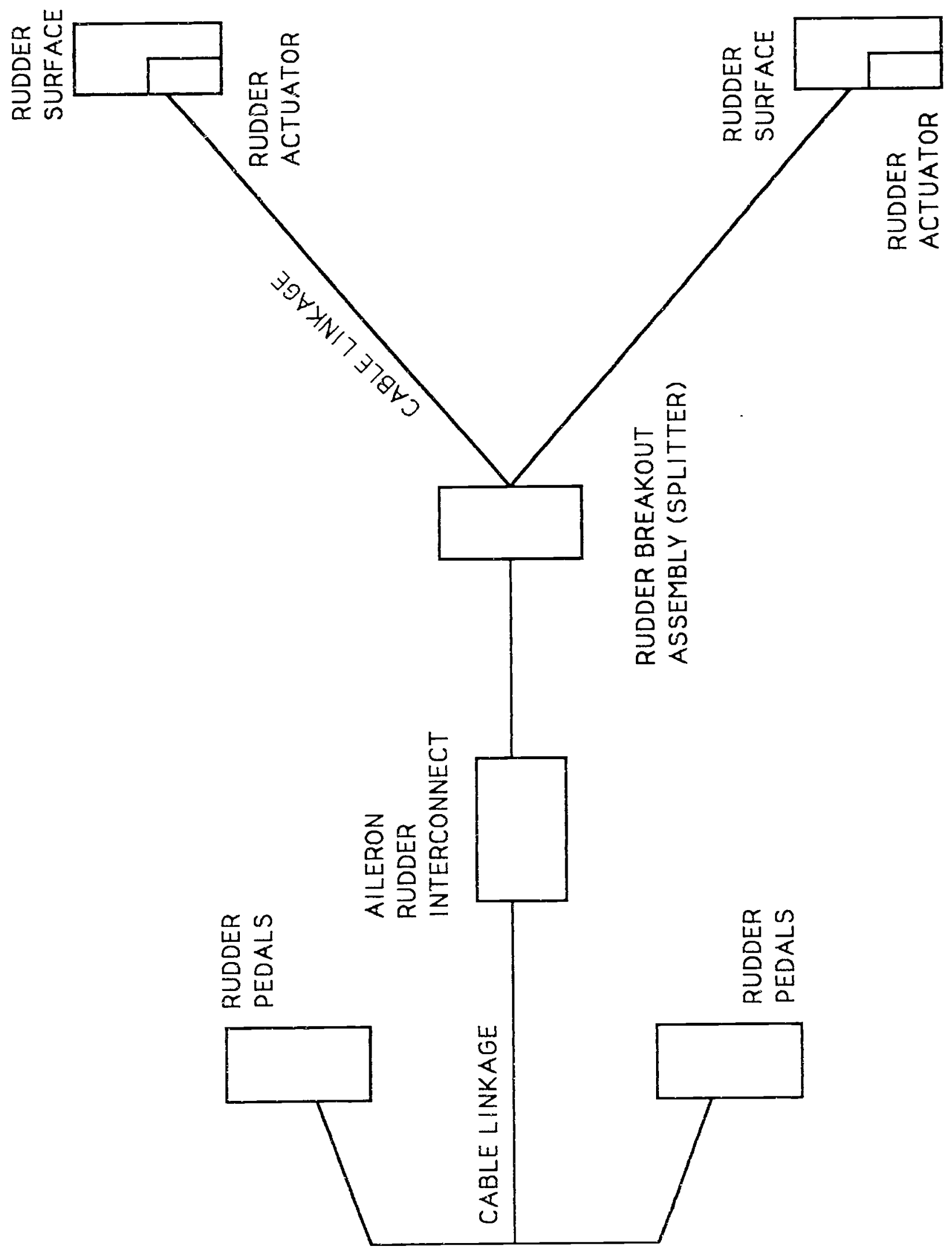


三

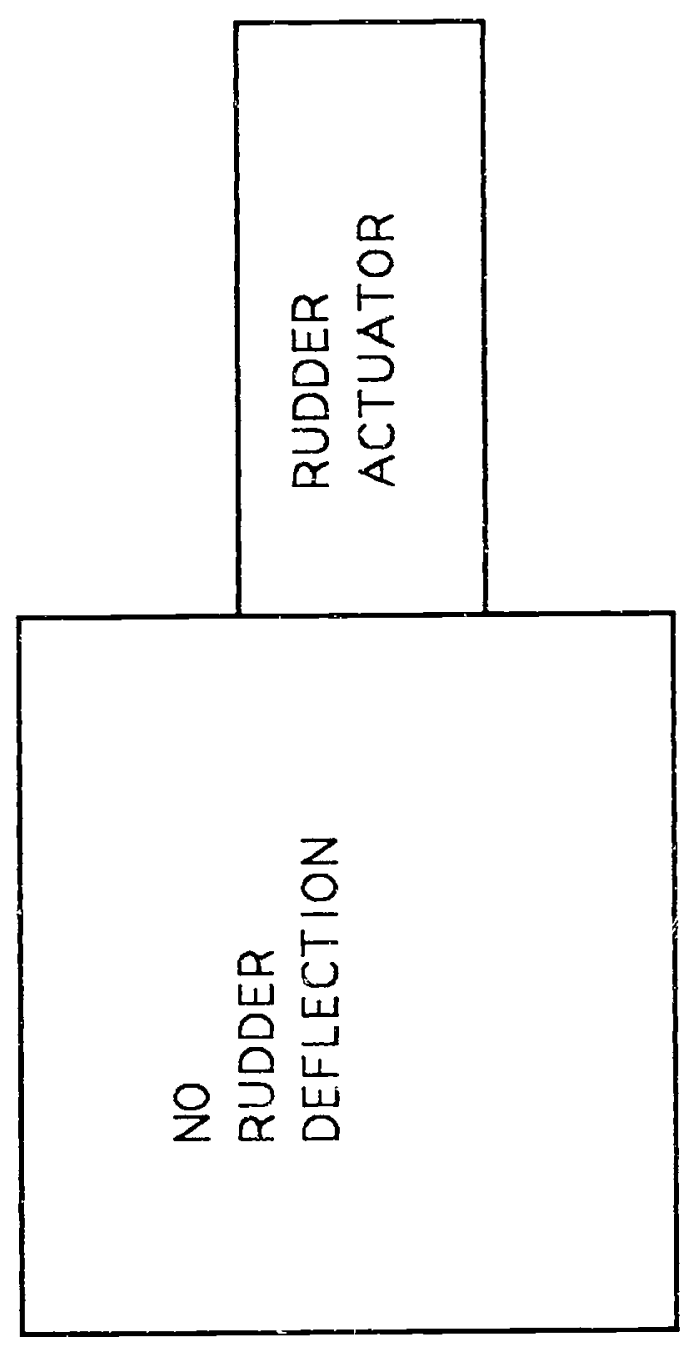

ERIC 


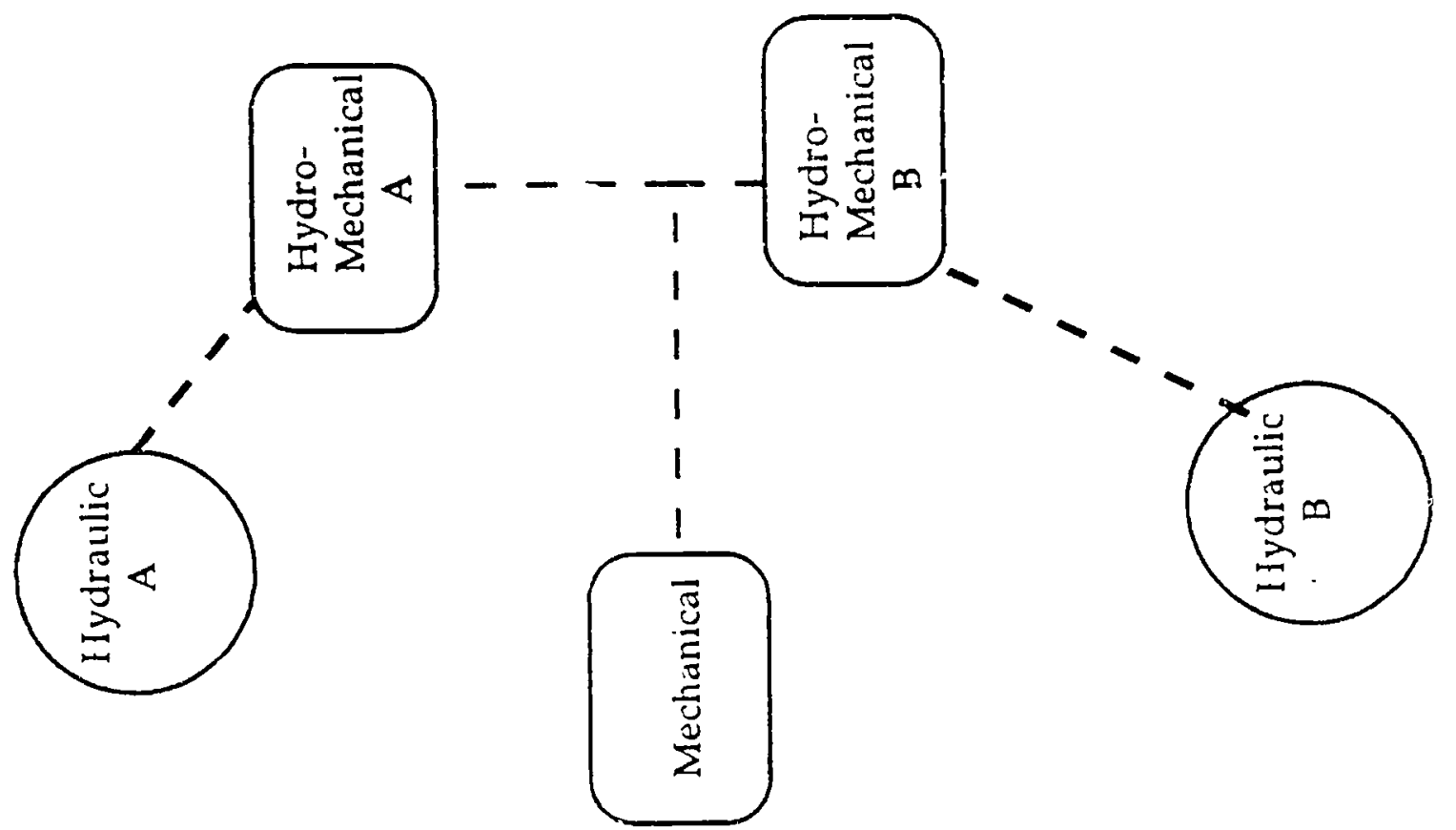


HYDRIVE's Strategic Goal Hierarchy

1. Power system elimination

2. Active path splitting

3. Power path splitting

4. Isolate failure within power path

a. Serial elimination

b. Remove and replace

$5:$ 


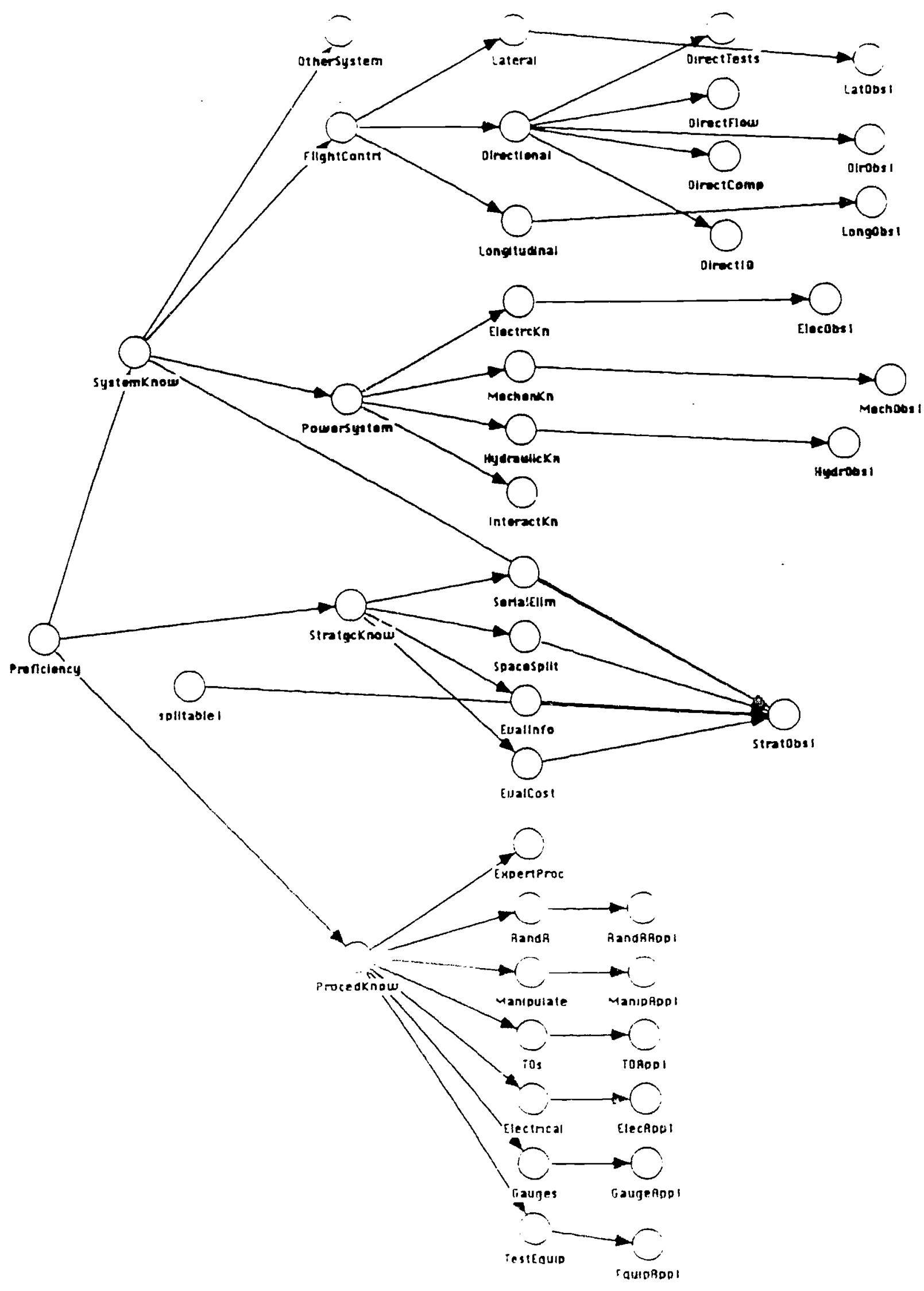




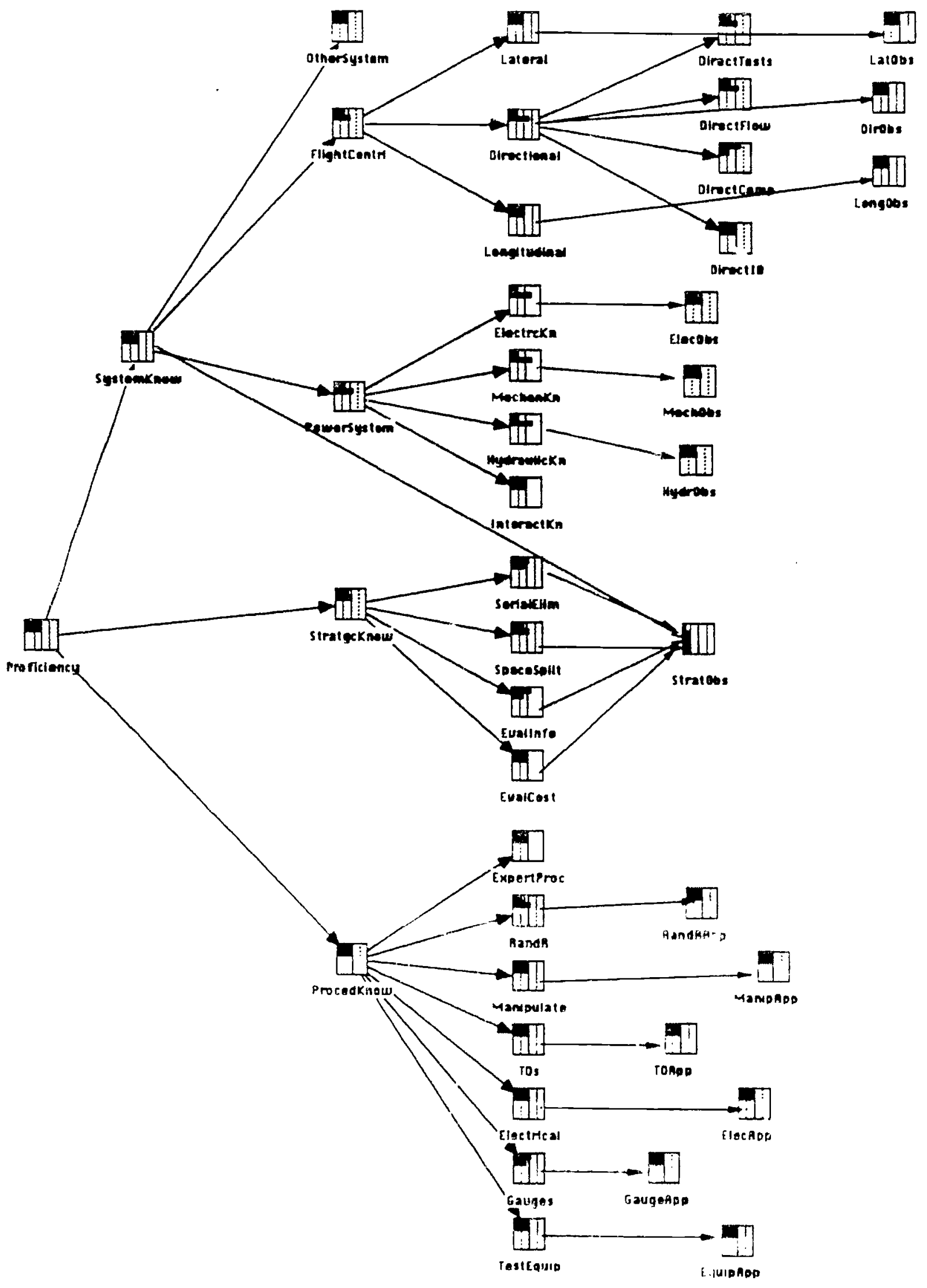

lparle for ineffective probtem solution 
Brophy 05 April 94

Dr Terry Ackerman

Educational Psychology

260C Education Bldg

University of lllinois

Champaign Il 61801

Dr Terry Allard

Code 3422

Office of Naval Research

$800 \mathrm{~N}$ Quincy St

Arlington VA $22217-5660$

Dr Nancy Allen

Educational Testing Service

Mail Stop 02-T

Princeton NJ 08541

Di Gregory Anrig

Educational Testing Service

Mail Stop 14-C

Princeton NJ 08541

Dr Phipps Arabie

Graduate School of Management

Rutgers University

92 New Street

Newark NJ 07102-1895

Dr Isaac I Bejar

Educational Testing Service

Mail Stop 11-R

Princeton NJ 08541

Dr William O Berry

Director

Life and Environmental Scicnces

AFOSR/NL N1

Bldg 410

Bolling AFB DC 20332.6448

Dr Thomas G Bever

Department of Psycbology

University of Rochester

River Station

Roxhester \$VY 14627

Di Menucha Birenladurn

School of Education

Tcl Avin Utiruersity

Kamat-Avir 69978 ISRAEL

Distribution List

Dr Bruce Bloxom

Defense Manpower Data Center

99 Pacific St

Suite 155A

Monterey CA $93943-3231$

Dr Gryneth Boodoo

Educational Testing Service

Mail Stop 03-T

Princeton NJ 08541

Dr Richard L Branch

HQ USMEPCOM/MEPCT

2500 Green Bay Road

North Cbicago IL 60064

Dr Robert Brennan

American College Testing

2201 North Dodge Street

PO Box 168

Iowa City LA 52243

Di David V Budescu

Department of Psychology

University of Haifa

Mount Carmel Haifa 31999

ISRAEL

Dr Gregory Candell

CTB/MaciMillan/McGraw.Hill

2:00 Garden Road

Montercy CA 93940

Dr Paul R Chatelier

PERCEPTRONICS

1911 ' lorth Fo Myer Drive

Suite 1100

Arlington VA 22209

Dr Susan Chipman

Cognitive Science Program

Office of Naval Recearcb

800 North Quincy Street

Code 3422

Arlington VA 22217.5660

Dr Raymond E Christal

UES LAMP Science Advisor

AL/HRMIL

Brooks AFB TX 78235
Dr Norman Cliff

Department of Psyciology

University of Southem California

Los Angeles CA 90089-1061

Director

Life Sciences

Code 3420

Office of Naval Researcb

Arlington VA $22217-5660$

Commanding Officer

Naval Research Laboratory

Code 4827

Washington DC 20375.5000

Dr Jobn M Cornwell

Department of Psychology

I/O Psychology Program

Tulane University

New Orleans LA 70118

Dr William Crano

Department of Psychology

Texas A\&M University

College Station TX 77843

Dr Linda Curran

Defense Manpower Data Center

Suite 400

1600 Wilson Blvd

Rosslyn VA 22209

Professor Clément Dassa

Faculté des sciences de l'éducation

Departement d'études en éducation

et d'administration de l'éducation

CP 6128 succursale $A$

Montéal Québec

CANADA $\mathrm{H} 3 \mathrm{C} 3 \mathrm{~J} 7$

Dr Timothy Davey

American College Testing

2201 North Dodge Street

PO Box 168

Iowa City LA 52243

Dr Charles E Davis

Educational Testing Service

Mail Stop 16-T

Princeton NJ 08541 
Di Ralph J DeAyala

Meas Stat and Eval

Benjamin Bldg Room 1230F

University of Maryland

College Park MD 20742

Dr Sharon Derry

Florida State University

Department of Psychology

Tallahassee FL 32306

Hei-Ki Dong

BELLCORE

6 Corporate Place

RM: PYA-1K207

PO Box 1320

Piscataway NJ 08855-1320

Dr Neil Dorans

Educational Testing Service

Mail Stop 07-E

Princeton NJ 08541

Di Fritz Drasgow

University of Illinois

Department of Psychology

603 E Daniel Street

Champaign II. 61820

Defense Tech Information Center

Cameron Station Bldg 5

Alexandria VA 22314

(2 Copies)

Di Richard Duran

Graduate School of Education

University of California

Santa Barbara CA 93106

Dr Susan Embretson

University of Kansas

Psychology Department

426 Fraser

Lawrence KS 66045

Dr George Engelhard $J_{r}$

Division of Educational Studies

Emory University

210 Fishbume Bldg

Allanta GA 30322
ERIC Facility-Acquisitions

2440 Research Blvd

Suite 550

Rockville MD 20850-3238

Dr Marshall J Farr

Farr-Sight Co

2520 North Vernon Street

Arlington VA 22207

Dr Leonard Feldt

Lindquist Center for Measurement

University of lowa

Iowa City IA 52242

Dr Richard L Ferguson

American College Testing

2201 North Dodge Street

PO Box 168

Iowa City IA 52243

Dr Gerhard Fischer

Liebiggasse 5

A 1010 Vienna

AUSTRIA

Dr Miyron Fischl

US Army Headquarters

DAPE-HR

The Pentagon

Washingtor DC 20310-0300

Mr Paul Foley

Navy Personnel R\&D Center

San Diego CA 92152-6800

Chair

Department of Computer Science

George Mason University

Fairfax VA 22030

Dr Robert D Gibbons

University of Illinois at Chicago

NPI 909A M/C 913

912 South Wood Street

Chicago IL 60612

Dr Janice Gifford

University of Massachusetts

School of Education

Amherst MA 01003
Di Robert Glaser

Learning Res \& Development Cntr

University of Pittsburgh

3.39 O'Hara Street

Pittsburgh PA 15260

Dr Susan R Goldrian

Peabody College

Box 45

Vanderoilt University

Nashville TN 37203

Dr Timothy Goldsmith

Department of Psychology

University of New Mexico

Albuquerque NM 87131

Dr Sherrie Gott

AFHRL/MOMJ

Brooks AFB TX 78235-5601

Dr Bert Green

Johns Hopkins University

Department of Psychology .

Charles \& 34th Street

Baltimore MD 21218

Professor Edward Haertel

School of Education

Stanford University

Stanford CA $94305-3096$

Dr Ronald K Hambleton

University of Massachusetts

Lab of Psychom \& Eval Res

Hills South Room 152

Amberst MA 01003

De Delwyn Hamisch

University of Illinois

51 Gerty Drive

Champaign IL 61820

Dr Patrick R Harrison

Computer Science Department

US Naval Academy

Annapolis MD 21402-5002

Ms Rebecca Hetter

Navy Personnel R\&D Center

Code 13

San Diego CA 92152-6800 
Dr Thomas M Hịsch

American College Testing

2201 North Dodge Street

PO Box 168

Iowa City IA 52243

Professor Paul W Holland

Div of Educ Psych \& Quant

Methods Prog

Graduate School of Education

4511 Tolman Hall

University of Califomia-Berkeley

Berkeley CA 94720

Professor Lutz F Hornke

Institut fur Psychologie

RWTH Aachen

Jaegerstrasse 17/19

D-5100 Aachen

WEST GERMANY

Ms Julia S Hough

Cambridge University Press

40 West 20th Street

New York NY 10011

Dr William Howell

Chief Scientist

AFHRL/CA

Brooks AFB TX 78235-5601

Dr Huynh Huynh

College of Education

University of South Carolina

Columbia SC 29208

Dr Martin J' el

Center for the w. . y of

Education and Instruction

Leiden University

PO Box 9555

2300 RB Leiden

THE NETHERLANDS

Dr Robert Jannarone

Elec and Computer Eng Dept

University of South Carolina

Columbia SC 29208
Dr Kumar Joag-dev

University of Illinois

Department of Statistics

101 Illini Hall

725 South Wright Street

Champaign II 61820

Professor Douglas H Jones

Grad Sch of Management

Rutgers The State University NJ

Newark NJ 07102.

Dr Brian Junker

Carnegie-Mellon University

Department of Statistics

Pittsburgh PA 15213

Dr Marcel Just

Carnegie-Mellon University

Department of Psychology

Schenley Park

Pittsburgh PA 15213

Dr J L Kaiwi

Code 442/JK

Naval Ocean Systems Center

San Diego CA 92152-5000

Dr Michael Kaplan

Office of Basic Research

US Army Researcb Institute

5001 Eisenhower Avenue

Alexandria VA 22333-5600

Dr Jeremy Kilpatrick

Dept of Mathematics Education

105 Aderhold Hall

University of Georgia

Athens GA 30602

Ms Hac-Rim Kim

University of Illinois

Department of Statistics

101 Illini Hall

725 South Wright Street

Champaign IL 61820

Dr. Jwa-keun Kim

Department of Psychology

Middle Tennessee State University

Murfreesboro TN 37132
Dr Sung-Hoon Kim

KEDI

92-6 Umyeon-Dong

Seocho-Gu

Seoul

SOUTH KOREA

Dr G Gage Kingsbury

Portland Public Schools

Res \& Eval Department

501 North Dixon Street

PO Box 3107

Portland OR 97209-3107

Dr William Koch

Box 7246

Meas \& Eval Center

University of Texas-Austin

Austin TX 78703

Dr James Kraatz

Computer-based Education

Research Laboratory

University of Illinois

Urbana IL 61801

Dr Patrick Kyllonen

AFHRL/MOEL

Brooks AFB TX 78235

Ms Carolyn Laney

1515 Spencerville Rod

Spencerville MD 20868

Richard Lanterman

Commandant (G-PWP)

US Coast Guard

2100 Second Street SW

Washington DC 20593-0001

Dr Michael Levine

Educational Psychology

210 Education Building

1310 South Sixth Street

Univ of IL at Urbana-Cuampaign

Champaign IL 61820-6990

Dr Charles Lewis

Educational Testing Service

Mail Stop 03-T

Princeton NJ 08541-0001 
Mr Hsin-hung Li .

University of Illinois

Department of Statistics

101 Illini Hall

725 South Wright Street

Champaign IL 61820

Library

Naval Training Systems Center

12350 Research Parkway

Orlando FL 32826-3224

Dr Marcia C Linn

Graduate School of Education

EMST

Tolman Hall

University of California

Berkeley CA 94720

Dr Robert L Linn

Campus Box 249

University of Colorado

Boulder CO 80309-0249

Logicon Inc (Attn: Library)

Tactical \& Training Systems Div

PO Box 85158

San Diego CA 92138-5158

Dr Richard Luecht

American College Testing

2201 North Dodge Street

PO Box 168

Iowa City IA 52243

Dr George B. Macready

Dept of Meas Stat \& Eval

College of Education

Uriversity of Maryland

College Park MD 20742

Dr Evans Mandes

George Mason University

4400 University Drive

Fairfax VA 22030

Dr Paul Mayberry

Center for Naval Analysis

4401 Ford Avenue

PO Box 16268

Alexandria VA 22302-0268
Dr James R McBride

HumRRO

6430 Elmhurst Drive

San Diego CA 92120

Mr Christopher McCusker

University of Illinois

Department of Psychology

603 E Daniel Street

Champaign IL 61820

Dr Joseph McLachlan

Navy Pers Res \& Dev Cntr

Code 14

San Diego CA 92152-6800

Alan Mead

c/o Dr Michael Levine

Educational Psychology

210 Education BIdg

University of Illinois

Champaign IL 61801

Dr Timothy Miller

American College Testing

2201 North Dodge Street

PO Box 168

Iowa City IA 52243

Dr Robert Mislevy

Educational Testing Service

Mail Stop 03-T

Princeton NJ 08541

Dr Ivo Molenar

Faculteit Sociale Wetenschappen

Rijksuniversiteit Groningen

Grote Kruisstraat 2/1

9712 TS Groningen

The NETHERLANDS

Dr Eiji Muraki

Educational Testing Service

Mail Stop 02-T

Princeton NJ 08541

Dr Ratna Nandakumar

Educational Studies

Willard Hall Room 213E

University of Delaware

Newark DE 19716
Acad Prog \& Research Branch

Naval Tech Training Command

Code N-62

NAS Memphis (75)

Millington TN 30854

Dr W Alan Nicewander

American College Testing

2201 North Dodge Street

PO Box 168

Iowa City LA 52243

Head

Pcrsonnel Systems Department

NPRDC (Code 12)

San Diego CA 92152-6800

Director

Training Systems Department

NPRDC (Code 14)

San Diego CA 92152-6800

Library NPRDC

Code 041

San Diego CA 92152-6800

Librarian

Naval Cntr for Applied Research in Artificial Intelligence

Naval Research Laboratory

Code 5510

Washington DC 20375-5000

Office of Naval Research

Code 3422

800 N Quincy Street

Arlington VA $22217-5660$

(6 Copies)

ONR Resident Representative

New York City

33 Third Avenue - Lower Level

New York NY 10003-9998

Special Asst for Res Managemeni

Chief of Naval Personnel

(PERS-01JT)

Department of the Navy

Washington DC 20350-2000

Dr Judith Orasanu

NASA Ames Research Center

Mail Stop 239-1

Moffett Field CA 94035 
Di Peter J Pashley

Law School Admission Services

PO Box 40

Newtown PA 18940-0040

Wayne M Patience

American Council on Education GED Testing Service Suite 20

One Dupont Circle NW

Washington DC 20036

Dept of Administrative Sciences

Code 54

Naval Postgraduate School

Monterey CA $93943-5026$

Dr Feter Pirolli

School of Education

University of Califomia

Berkeley CA 94720

Dr Mark D Reckase

American College Testing

2201 North Dodge Street

PO Box 168

Iowa City IA 52243

Mr Steve Reise

Department of Psychology

University of Califomia

Riverside CA 92521

Mr Louis Roussos

University of Illinois

Department of Statistics

101 Illini Hall

725 South Wright Street

Cùampaign II. 61820

Dr Donald Rubin

Statistics Department

Science Center Room 608

1 Oxford Street

Harvard University

Cambridge MA 02138

Dr Fumiko Samejima

Department of Psychology

University of Tennessee

310B Austin Peay Bldg

Knoxville TN 37966-0900
Dr Mary Schratz

4100 Parkside

Carlsbad CA 92008

Mir Robert Semmes

N218 Elliott Hall

Department of Psychology

University of Minnesota

Minneapolis MN 55455-0344

Dr Valerie L Shalin

Dept of Industrial Engineering

State University of New York

342 Lawrence D Bell Hall

Buffalo NY 14260

Mr Richard J Shaveison

Graduate School of Education

University of California

Santa Barbara CA 93106

Kathleen Sheehan

Educational Testing Service

Mail Stop 03-T

Princeton NJ 08541

Dr Kazuo Shigemasu

7-9-24 Kugenuma-Kaigan

Fujisawa 251

JAPAN

Dr Randall Shumaker

Naval Research Laboratory

Code 5500

4555 Overlook Avenue SW

Washington DC 20375.5000

Dr Judy Spray

Aurerican College Testing

2201 North Dodge Street

PO Box 168

Iowa City LA 52243

Dr Martha Stocking

Educationai Testing Service

Mail Stop 03-T

Princeton NJ 08541

Dr William Stout

University of Ullinois

Department of Statistics

101 Illini Hall

725 South Wright St

Champaign IL 61820
Dr Kikumi Tatsuoka

Educational Testing Service

Mail Stop 03-T

Princeton NJ 08541

Dr David Thissen

Psychometric Laboratory

CB\# 3270 Davie Hall

University of North Carolina

Chapel Hill NC 27599-3270

Mr Thomas J Thomas

Federal Express Corporation

Human Resource Development

3035 Director Row Suite 501

Memphis TN 38131

Mr Gary Thomasson

University of Illinois

Educational Psychology

Champaign IL 61820

Dr Howard Wainer

Educational Testing Service

15-T Rosedale Road

Princeton NI 08541

Elizabeth Wald

Office of Naval Technology

Code 227

800 North Quincy Street

Arlington VA 22217-5000

Dr Michael T Waller

Univ of Wisconsin-Milwaukee

Educ Psychology Department

Box 413

Milwaukec WI 53201

Dr Ming-Mei Wang

Educational Testing Service

Mail Stop 03-T

Princeton NJ 08541

Dr Thomas A Warm

FAA Academy

PO Box 25082

Oklahoma City OK 73125

Dr David I Weiss

N660 Elliott Hall

University of Minnesota

75 E River Road

Minneapolis MN 55455-0344 
Dr Douglas Wetzel

Code 15

Navy Personnel R\&D Center

San Diego CA 92152-6800

German Military Representative

Personalstammamt

Koelner St 262

D-5000 Koeln 90

WEST GERMANY

Dr David Wiley

Sch of Educ and Social Policy

Northwestern University

Evanston II 60208

Dr Bruce Williams

Dept of Educational Psychology

University of Ilinois

Urbana IL 61801

Dr Mark Wilson

School of Education

University of California

Berkeley CA 94720

Dr Eugene Winograd

Department of Psychology

Emory University

Atlanta GA 30322

Dr Martin F Wiskoff

PERSEREC

99 Pacific Street

Suite $\mathbf{4 5 5 6}$

Monterey CA 93940

Mr John $\mathrm{H}$ Wolfe

Navy Personnel R\&D Center

San Diego CA 92152-6800

Dr Kentaro Yamamoto

Educational Testing Service

Mail Stop 03-T

Princeton NJ 08541

Duanli Yan

Educational Testing Service

Mail Stop 03-T

Princeton NJ 08541
Dr Wendy Yen

CTB/McGraw Hill

Del Monte Research Park

Monterey CA 93940

Dr Joseph L Young

National Science Foundation

Room 320

1800 G Street NW

Washington DC 20550 